\title{
Aerothermodynamic Measurement and Prediction for Modified Orbiter at Mach 6 and 10 John R. Micol
}

Reprinted from

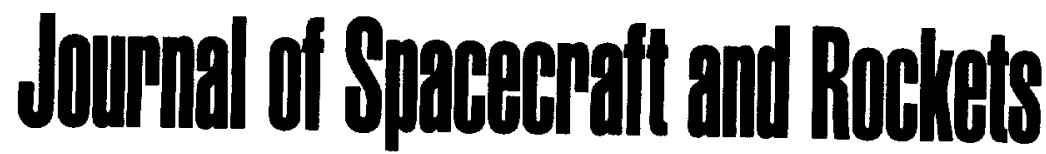

Volume 32, Number 5 , Pages 737-748

\section{OAIAA.}

A publication of the

American Institute of Aeronautics and Astronautics, Inc.

370 L'Enfant Promenade, SW

Washington, DC 20024-2518 



\title{
Aerothermodynamic Measurement and Prediction for Modified Orbiter at Mach 6 and 10
}

\author{
John R. Micol* \\ NASA Langley Research Center, Hampton, Virginia 23681-0001
}

\begin{abstract}
Detailed heat-transfer rate distributions measured laterally over the windward surface of an orbiter-like configuration using thin-film resistance heat-transfer gauges and globally using the newly developed relative intensity, two-color thermographic phosphor technique are presented for Mach 6 and 10 in air. The angle of attack was varied from 0 to $40 \mathrm{deg}$, and the freestream Reynolds number based on the model length was varied from $4 \times 10^{5}$ to $6 \times 10^{6}$ at Mach 6, corresponding to laminar, transitional, and turbulent boundary layers; the Rey nolds number at Mach 10 was $4 \times 10^{5}$, corresponding to laminar flow. The primary objective of the present study was to provide detailed benchmark heat-transfer data for the calibration of computational fluid-dynamics codes. Predictions from a Navier-Stokes solver referred to as the Langley aerothermodynamic upwind relaxation algorithm and an approximate boundary-layer solving method known as the axisymmetric analog three-dimensional boundary layer code are compared with measurement. In general, predicted laminar heat-transfer rates are in good agreement with measurements.
\end{abstract}

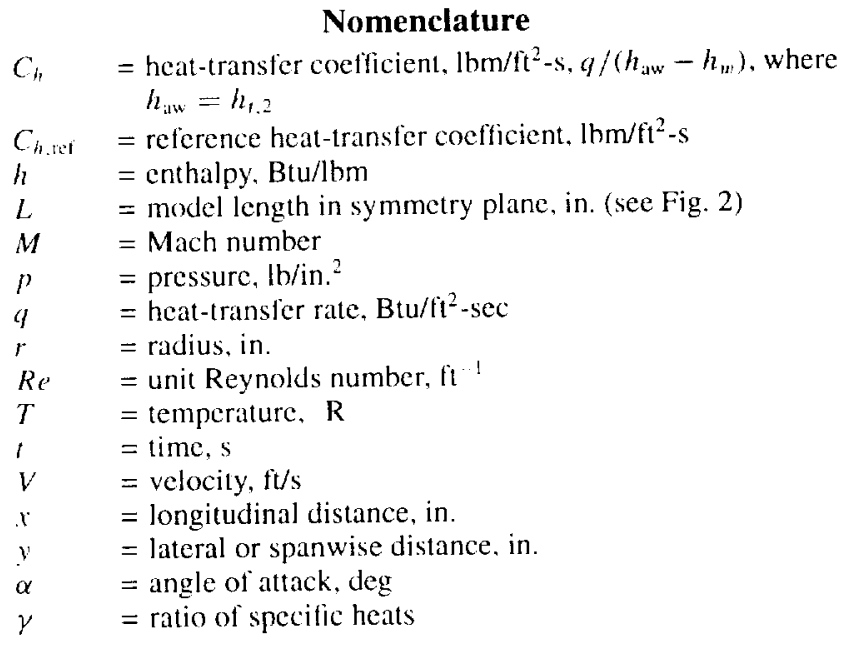

Sutweripts

aw = adiabatic wall

b $\quad$ base

$L \quad=$ based on model length in symmetry plane

$1.1=$ reservoir conditions

t.2 = stagnation conditions behind the normal shock

$w=$ model surface; wall surface

$2=$ static conditions behind the normal shock

$\infty=$ freestream static conditions

\section{Introduction}

$\mathbf{F}$ OR many years, the Langley Research Center has been involved in the study of Earth-to-orbit space transportation concepts that fulfill a variety of anticipated mission needs. Some examples are programs such as the Assured Crew Return Vehicle (ACRV), a vehicle

Presented as Paper 91-1436 at the AJAA 26th Thermophysics Conference, Honolulu. HI, June 24-27, 1991; received June 6, 1993; revision received March 16. 1994; accepted for publication March 16, 1994. Copyright (C) 1990 by the American Institute of Aeronautics and Astronautics, Inc. No copyright is asserted in the United States under Title 17, U.S. Code. The U.S. Government has a royalty-free license to exercise all rights under the copyright claimed herein for Governmental purposes. All other rights are reserved by the copyright awner.

*Aerospace Engineer, Aerothermodynamics Branch, Gas Dynamics Division. Member AIAA. designed to return crew members from Space Station Freedom; the Personnel Launch System (PLS), a personnel carrier to low Earth orbit and return; and Advanced Manned Launch Systems, a candidate replacement for the current Space Shutlle Orbiter (see for example. Refs. 1-4). From an aerodynamic/aerothermodynamic perspective. these programs will benefit from knowledge gained as a result of the comprehensive data base established for the Space Shuttle program. Therefore, it is important that computational, ground-based, and flight data bases be brought together in an effort to gain an accurate knowledge of flow field phenomena associated with the space transportation system. The impetus for this work is to provide improvements to current computational fluid-dynamic techniques and to ground-to-flight extrapolation techniques that would be applied to the next space transportation system.

The present study augments the well-established comprehensive aerothermodynamic data base for the Shuttle Orbiter by providing additional information concerning the complex three-dimensional windward flowfield for an orbiter-like configuration. Areas of interest include transition from laminar to turbulent boundary-layer heating phenomena and shock-shock interaction phenomena on windward-surface heating distributions. To date, most comparisons of aerothermodynamic results obtained via ground-based measurements, predictions, and orbiter flight data have focused on the windward symmetry plane; similar comparisons for systematic spanwise heating are quite scarce. For the present study, detailed spanwise heat-transfer distributions were measured over the windward surface of a winged lifting entry configuration referred to herein as a modified orbiter. The objective of the present study is to compare predicted heating distributions from computational fluid-dynamics (CFD) codes with these detailed spanwise heating measurements. A set of high-fidelity modified orbiter models using the thin-film resistance gauge technique have been designed, fabricated, instrumented, and tested in two wind tunnels of the Langley Hypersonic Facilities Complex to obtain detailed aerothermodynamic data over a wide range of test conditions. The discrete heat-transfer measurements obtained using thin-film gauges are augmented by global thermal mappings and qualitative heat-transfer mappings obtained with the recently developed relative-intensity, two-color thermographic phosphor technique. These measurement techniques nicely capture the previously documented streak-heating phenomena resulting from the upstream effects of bow-shock-wing-shock interaction.

\section{Experimental Method}

Facilities

The Langley 20-Inch Mach 6 Tunnel is a blowdown wind tunnel that uses dry air as the test gas. The air is heated to a maximum 
temperature of $1088 \mathrm{R}$ by an electrical resistance heater, and the maximum reservoir pressure is 525 psia. A fixed-geometry, twodimensional, contoured nozzle with parallel side walls expands the flow to Mach 6 at the 20 -in.-square test section. This tunnel is equipped with a bottom-mounted model injection-retraction system capable of injecting heat-transfer models from a sheltered position to the nozzle centerline in less than $0.6 \mathrm{~s}$. The run time for this facility varies from 2 to $10 \mathrm{~min}$. A description of this facility and calibration results are presented in Ref. 5.

The Langley 31-Inch Mach 10 Tunnel, formerly known as the Langley Continuous-Flow Hypersonic Tunnel, ${ }^{6}$ is a blowdown facility having a run time of approximately $60 \mathrm{~s}$. The facility uses a water-cooled, three-dimensional contoured nozzle to generate a nominal Mach number of 10 at the 31-in.-square test section. Dry air is used as the test gas and is heated to a maximum reservoir stagnation temperature of $1900^{\circ} \mathrm{R}$. The maximum reservoir pressure is 1450 psia. The tunnel is equipped with a side-wall-mounted model injection-retraction system. Models are sheltered in the injection chamber on the side of the tunnel until the tunnel flow is started. After establishing Mach 10 flow at the test section, heat-transfer models are injected into the highly uniform stream within $0.5 \mathrm{~s}$.

\section{Models}

Heat-transfer distributions were measured on the windward surface of a 0.0075 -scale (9.09-in. length) model of a Shuttle-like

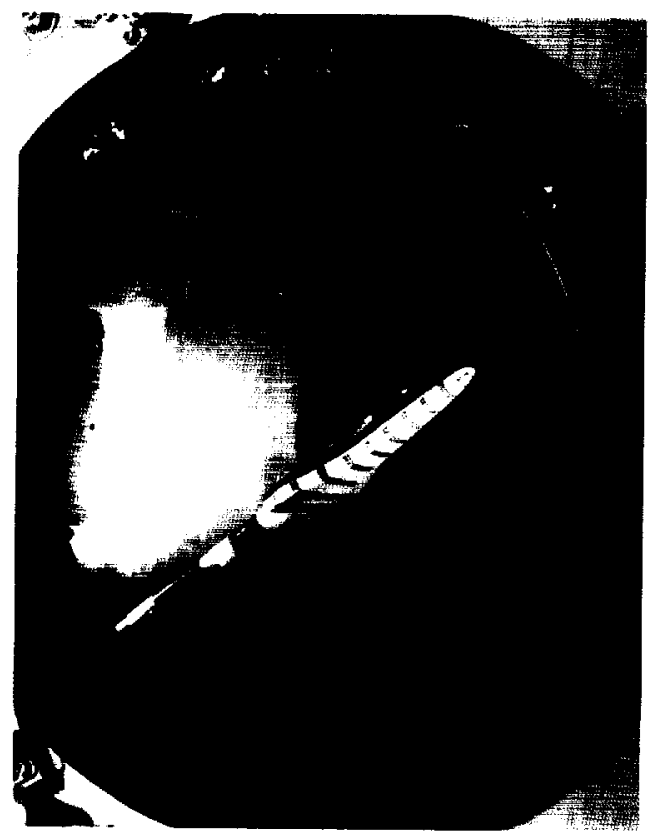

a) Glass-ceramic model

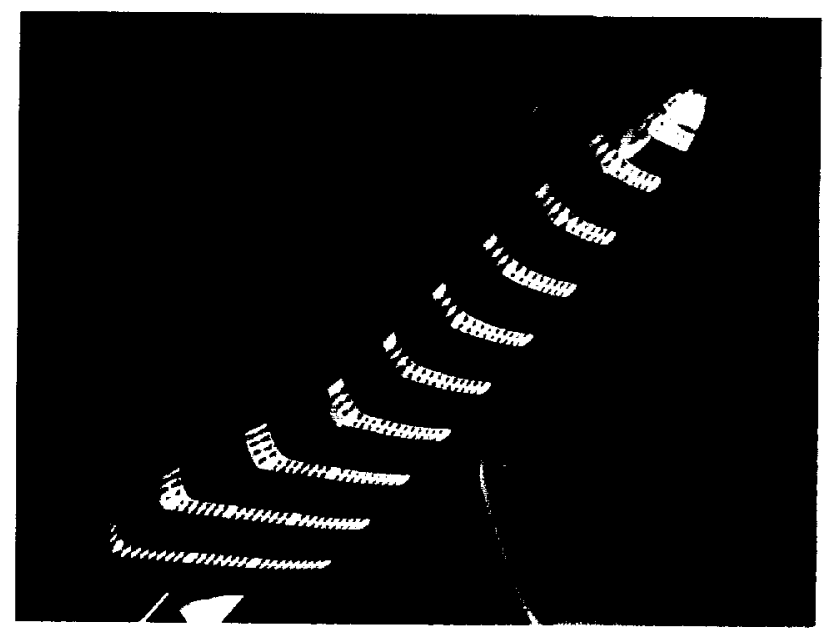

b) Stainless-steel model with glass-ceramic inserts

Fig. 1 Photograph of modified orbiter.

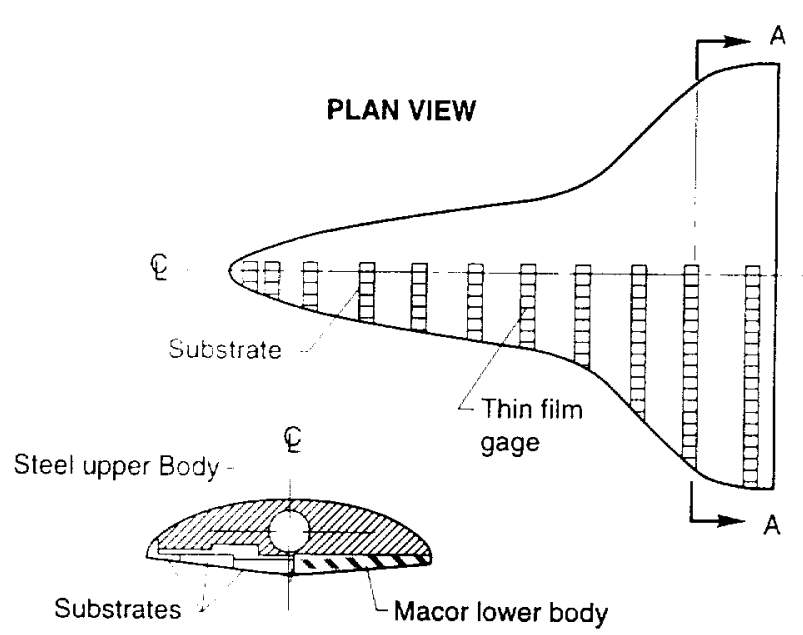

Section A-A

Fig. 2 Sketch of spanwise heating model.

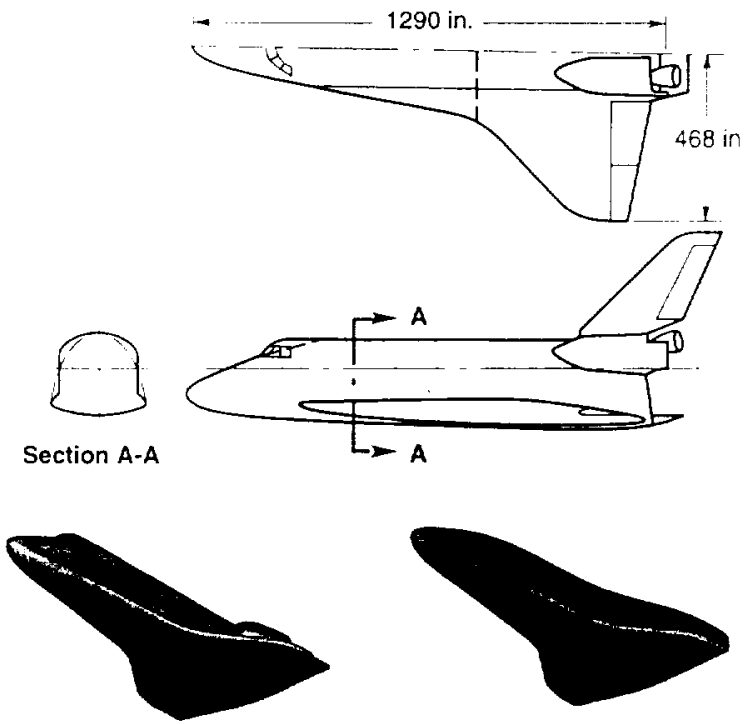

a) Complete geometry

b) Modified geometry

Fig. 3 Space Shuttle Orbiter geometry. Dashed lines represent fairings to model leeward side in present study.

configuration. A photograph and a sketch of the model are presented in Figs. 1 and 2, respectively. The model has the same lower shape as the forward $93 \%$ of the Shuttle Orbiter. However, the upper surface is defined by elliptical cross sections. As shown in Fig. 3, the orbiter canopy has been faired and the vertical tail and OMS pods omitted.

Two 9.09-in.-length models, referred to herein as the modified orbiters, were fabricated. Both models had solid steel upper surfaces; however the lower surfaces of the two models differed. One model was machined entirely of steel and then slotted to accept machinable glass-ceramic substrates (herein referred to as the slotted stainless-steel model), whereas the second model was unique being machined entirely from the ceramic material and slotted to accept the machinable glass-ceramic substrates (herein referred to as the slotted ceramic model).

Both models were cut on a numerical milling machine using a tape generated with the geometry program described in Ref. 7 . Since this program was also used to generate the geometry in the CFD codes (to be discussed subsequently), differences between the experimental and computational models were within the machining tolerance of $\pm 0.003 \mathrm{in}$.

\section{Test Conditions}

For this study, the pitot pressure could not be conveniently measured when the model was positioned in the test-section of the 31-Inch Mach 10 Tunnel. Thus, test-section flow conditions were 
Table 1 Nominal reservoir and freestream flow conditions

\begin{tabular}{|c|c|c|c|c|c|c|c|}
\hline$M_{\infty}$ & $\begin{array}{c}p, 1, \\
p s i\end{array}$ & $\begin{array}{l}T_{t, 1} \\
\mathrm{R}\end{array}$ & $\begin{array}{l}p_{\infty} \\
p s i\end{array}$ & $\begin{array}{c}T_{X} \\
\mathrm{R}\end{array}$ & $\begin{array}{c}\operatorname{Re}_{\infty} L \\
10^{-5}\end{array}$ & $T_{w} / T_{t, 2}$ & $\begin{array}{c}C_{\text {h.ref. }} \\
10^{-5} \mathrm{Btu}-\mathrm{s} / \mathrm{ft}^{4}\end{array}$ \\
\hline 5.82 & 29 & 872 & 0.022 & 112.2 & 4.16 & 0.62 & 0.276 \\
\hline 5.94 & 127 & 915 & 0.086 & 113.6 & 17.21 & 0.59 & 0.556 \\
\hline 5.98 & 253 & 911 & 0.163 & 111.7 & 33.28 & 0.59 & 0.772 \\
\hline 6.01 & 475 & 931 & 0.297 & 113.2 & 59.79 & 0.58 & 1.050 \\
\hline 9.75 & 354 & 1822 & 0.009 & 94.9 & 4.17 & 0.30 & 0.326 \\
\hline
\end{tabular}

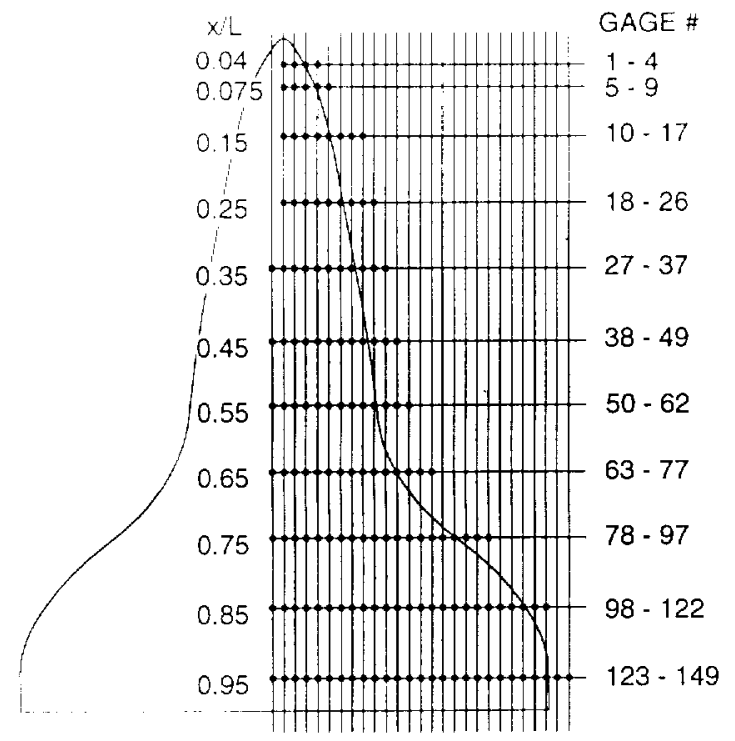

$y / L$

Fig. 4 Layout of thin-film instrumentation.

based on measured reservoir pressures and temperatures and a recent unpublished calibration of the facility.

Flow conditions in the 20-Inch Mach 6 Tunnel were determined from the measured reservoir pressure and temperature and the measured pitot pressure at the test section.

Nominal reservoir stagnation and corresponding freestream flow conditions for the present study are presented in Table 1 . The value of $L$ used to determine $R e_{\infty, L}$ is 9.09 in.

The stainless-steel and ceramic models were tested over a range of angles of attack from 0 to 40 deg in 10-deg increments for each flow condition at Mach 6. Due to time constraints on testing in the 31Inch Mach 10 Tunnel, only the stainless-steel model was tested at Mach 10; this model was tested at angles of attack equal to $0,10,15$, 20 , and $30 \mathrm{deg}$. The sideslip angle was zero for all tests. The angle of attack was measured relative to the model centerline (see Fig. 2).

\section{Instrumentation and Testing Techniques}

Thin-Film Gauges

Thin-film resistance heat-transfer gauges were used to measure surface temperature-time histories from which heat-transfer rates were inferred. The technology of the thin-film gauges remains unchanged from that developed for the Langley Expansion Tube. ${ }^{8.9}$ The model surface contained 149 palladium gauges $(0.04$ by 0.05 in.), each approximately $1000 \AA$ thick. These gauges were deposited on highly polished substrates that were precision-fitted to the model. The model substrate thickness was sized to provide a maximum run time of $1.5 \mathrm{~s}$; that is, the substrate essentially behaves as a semi-infinite slab for $1.5 \mathrm{~s}$ over most of the forebody. An aluminum oxide overlayer, approximately $5000 \AA$ thick, was deposited over the sensing elements as a means of increasing the gauge durability. Detailed discussions of gauge construction, circuilry, and calibration procedures and the data acquisition system are discussed in Rels, 8 and 9. The instrumentation layout is presented in Fig. 4.

\section{Thermographic Phosphor Technique}

The relative-intensity two-color thermographic phosphor technique ${ }^{1 / 1} 12$ is rapidly becoming the most widely used heal-transfer measurement technique in the Hypersonic Facilities Complex at Langley. ${ }^{13}$ The model, generally MACOR, stycast, or ceramic (fused silica), is coated with thermographic phosphors. When illuminated with ultraviolet light, electrons are excited and emit visible light during their subsequent relaxation to lower energy levels. The probability that the relaxation and subsequent fluorescence cmission, will occur is temperature-dependent, and the intensity of fluorescence may be used to determine local temperatures. Phosphor materials are selected for a two-color emission-band spectrum that matches front-end filters on conventional color video cameras. A three-chip, co-site sampling CCD camera, which has true color separation in the red, green, and blue bands and spatially congruent detection arrays is used. Early applications of this technique utilized thermographic phosphors having secondary and primary emission bands at 450 and $520 \mathrm{~nm}$, respectively (i.e., blue-green). Two materials were used, one with a temperature sensitivity range of 520 to $710 \mathrm{R}$ and the other with a range of 560 to $810^{\circ} \mathrm{R}$. Currently, a mixture is used consisting of both a broadband phosphor and a narrowband rare-carth phosphor. For this mixture, the green and red camera filters are used, and a temperature sensitivity range of 480 to $860 \mathrm{R}$ is obtained. The camera response is calibrated versus incident intensity. Measured intensities from two of the camera color outputs are used to form the intensity ratio from which quantitative temperature information may be determined using digital processing. Heating rates are calculated from surface temperature measurements using one-dimensional semi-infinite solid heat-conduction equations, as is discussed in detail in Refs. 11 and 12. Based on considerations presented in Rets. 12 and 14 , the uncertainty in the heating coefficients is $\pm 15 \%$.

For this study, the heat-transfer model was cast from a high-purity fused-silica ceramic using an investment slip-casting technique described in Refs. 11 and 15. The slip casting forms a ceramic shell, which is then heat-treated to $2600^{\circ} \mathrm{R}$. A hydraulically setting magnesia ceramic is used to backfill the ceramic shell, thus providing strength and support to the sting structure. The phosphor mixlure is suspended in a colloidal silica binder and spray-coated on the model surface. Typical coating thicknesses vary from 0.001 to 0.003 in.

\section{Data Reduction and Uncertainty}

The numerical method used to compute values of the heat-1ransfer rate $q$ from the output of the thin-film resistance gauges is discussed in Refs. 9 and 16. A more accurate determination of the thermal properties of the glass-ceramic material ${ }^{17}$ was used to reduce the data for the present study from those presented in Ref. 9. Sample time historics for gauges along the windward centerline revealed that the heat-transfer coefficient $C_{h}$ was essentially constant (i.e., within $\pm 2 \%$ ) over the time interval from 0.5 to $1.7 \mathrm{~s}$; that is, the substrate behaved one-dimensionally. Second-order least-squares curve fits were applied to time histories of $q$ for $0.5<t<1.7$ $\mathrm{s}$, and values of $q$ (or $C_{h}$ ) presented herein were obtained from these curve fits and generally correspond to $t=1.1 \mathrm{~s}$. For gauges along the planform leading edge, $C_{h}$ was observed to increase with time for $t>0.7 \mathrm{~s}$, indicating that gauges in this region of small surface radius do not behave one-dimensionally. as expected. However, for $0.5 \mathrm{~s} \leq t \leq 0.7 \mathrm{~s}, C_{h}$ was essentially constant with time; thus values of $q\left(\right.$ or $\left.C_{h}\right)$ for gauges at the planform leading edge correspond to $t=0.5 \mathrm{~s}$. Heating distributions are presented in terms of the ratio of heat-transfer coefficients $C_{h} / C_{h, \text { ref }}$, where $C_{h, \text { ref }}$ corresponds to the stagnation-point heat-transfer rate to a sphere with a radius of $0.2067 \mathrm{in}$. For this 0.0075 -scale model, the nose radius (i.e., equivalent sphere radius) was determined to be $0.2067 \mathrm{in}$. This value was determined by scaling the approximate equivalent sphere radius for the full-scale Space Shuttle Orbiter nose, which is about 


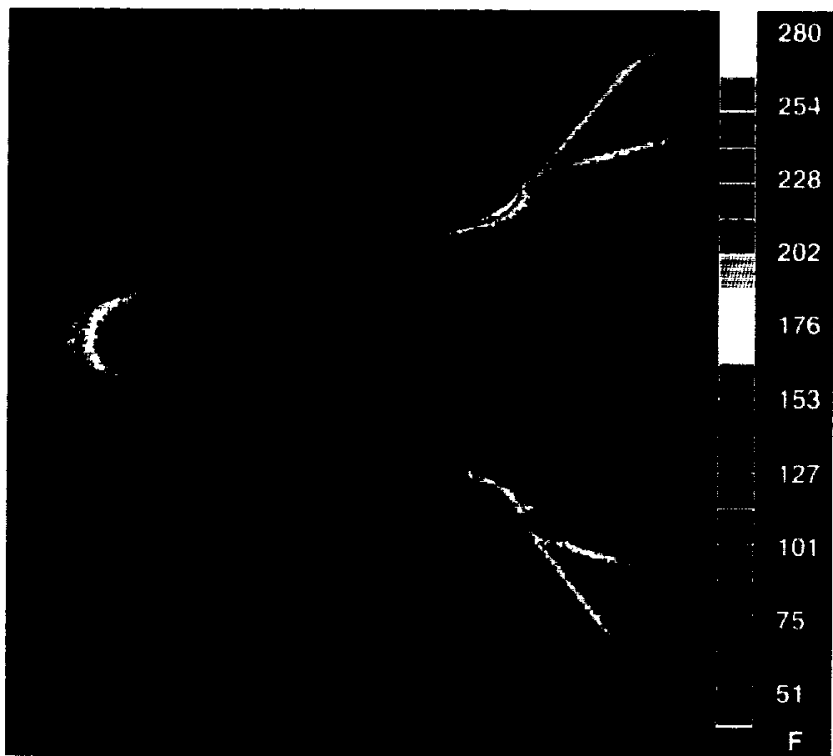

a) $\alpha=15 \mathrm{deg}$

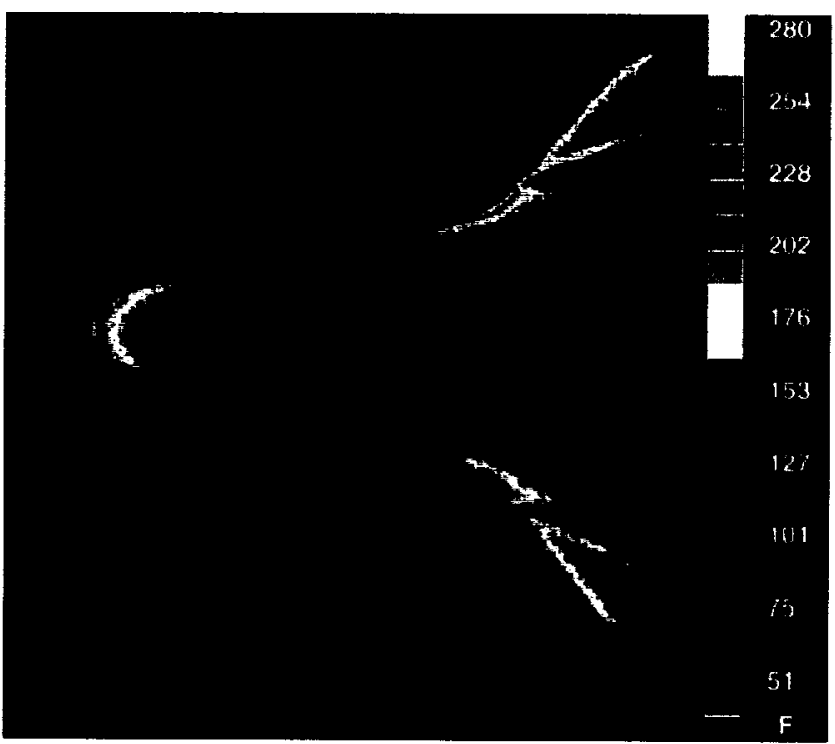

b) $\alpha=20 \mathrm{deg}$

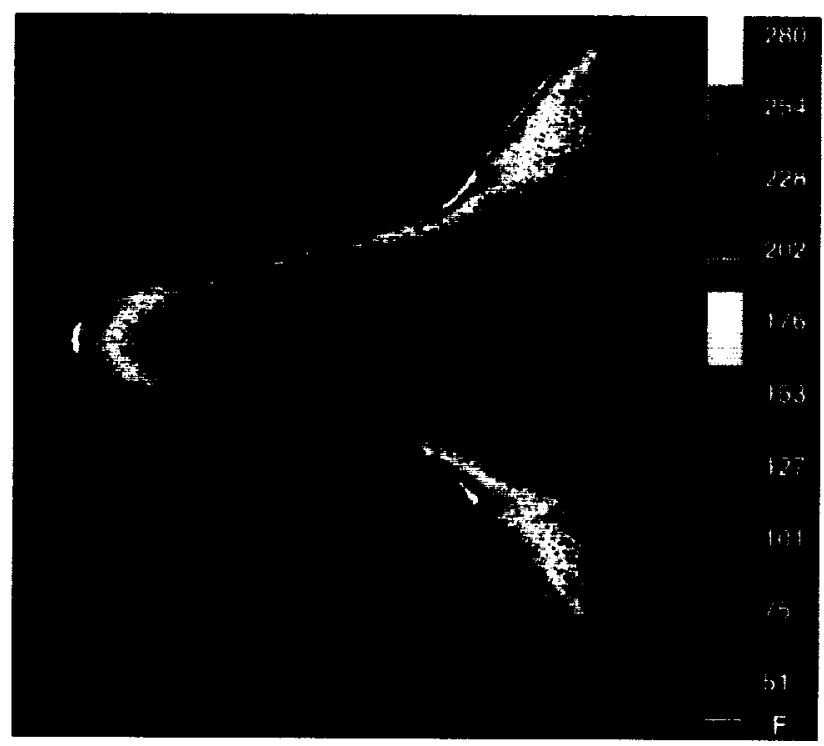

c) $\alpha=30 \mathrm{deg}$

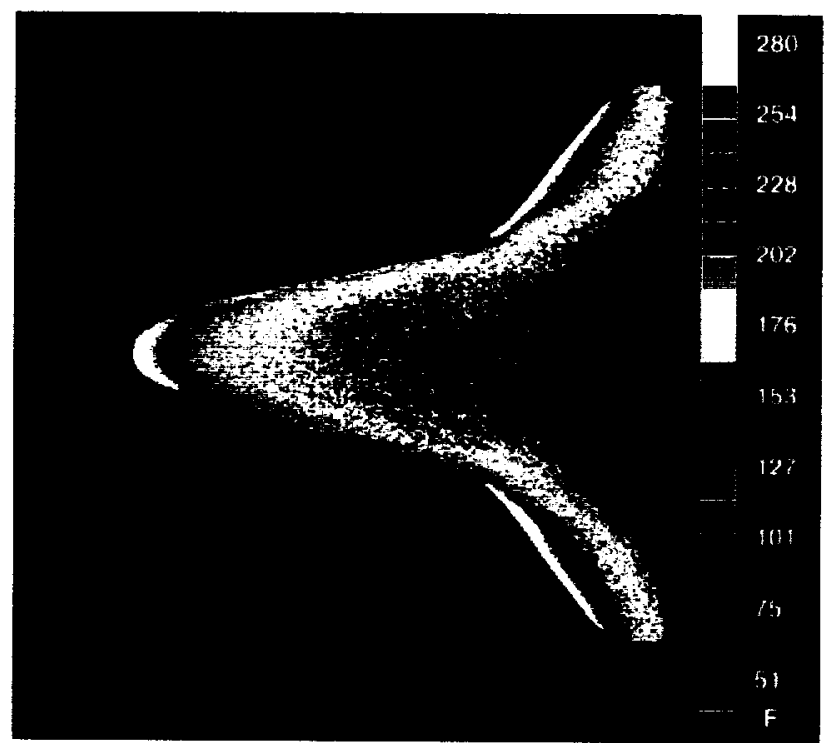

d) $\alpha=40 \mathrm{deg}$

Fig. 5 Global surface-temperature mappings of the windward surface of the modified orbiter using the two-color thermographic phosphor technique at Mach 10 and $\operatorname{Re}_{\infty, L}=4.2 \times 10^{5}$.

27.6 in. (Ref. 18). Values of $C_{h, \text { ref }}$ (see Table 1) were computed with the theory of Fay and Riddell ${ }^{19}$ and correspond to a wall temperature of $540 \mathrm{R}$ (that is, to an isothermal model). This method of presenting the measured heating (i.e., $T_{w}=540^{\circ}$ R) was possible because the measured heat-transfer coefficient was constant with time. ${ }^{17}$ Run-torun repeatability for the thin-film heat-transfer technique for $\alpha=0$ and a Reynolds number of $4.16 \times 10^{5}$ at Mach 6 was within $\pm 1.1 \%$; for $R e_{x . L}=17.21 \times 10^{5}$, a maximum run-to-run variation of $\pm 3.5 \%$ was noted. Probable sources of error for thin-film resistance gauges are discussed in Rels. 9 and 20. Based on these discussions and the present run-to-run variations, the heat-transfer rates presented hercin are believed accurate to within $\pm 8 \%$ for all measured data.

\section{Prediction Methods}

\section{AA3DBL Code}

Surface heating rates for the modified orbiter geometry were calculated using the axisymmetric analog for three-dimensional boundary layers developed by Cooke ${ }^{21}$ and applied by Hamilton et al. ${ }^{22}$ The method is known as the AA3DBL, or axisymmetric analog three-dimensional boundary-layer, code. In using the AA3DBL code, several assumptions are made. As discussed in Ref. 22, the general, three-dimensional boundary-layer equations are written along a streamline. If the crossflow velocity in the boundary layer is neglected, the boundary-layer equations reduce to the axisymmetric form, provided that the distance along a streamline is interpreted as the distance along an equivalent body and the metric that describes the spreading of the streamlines is interpreted as the radius of the equivalent axisymmetric body. This allows any axisymmetric boundary-layer solution to be used to calculate the approximate three-dimensional heating rates along streamlines. Thus, the heating over a complete vehicle can be computed by considering multiple streamline paths at a fraction of the cost that would be incurred if the full three-dimensional boundary-layer equations were used.

Streamline information and boundary-layer-edge properties are acquired from the inviscid HALIS code. ${ }^{23}$ No iteration is considered between the boundary layer and inviscid solutions; thus, the Reynolds numbers must be reasonably large so that the boundarylayer solution does not strongly affect the inviscid solution. A rapid, approximate integral method ${ }^{24}$ is used to calculate the heating along individual streamlines. For this study, HALIS/AA3DBL was executed for a perfect gas. The approximate run time for the HALIS code using a grid of $15 \times 73 \times 145$ is $0.8 \mathrm{~h}$ on the Cray Y-MP computer for this configuration. The AA3DBL code requires approximately $0.2 \mathrm{~h}$ on a Sun SPARC 2 using 145 streamlines. ${ }^{25}$ 


\section{LAURA Code}

Surlace heating rates for the modified orbiter geometry were also calculated using the Langley aerothermodynamic upwind relaxation algorithm (LAURA). This code has been continually improved over the past few years and is described in detail in Refs. 26-29. (The latest version of the code is described in Ref. 29.) LAURA is a finite-volume-based algorithm that employs a point-implicit relaxation procedure for obtaining the numerical solution to the governing equations (Navier-Stokes) for three-dimensional, viscous, hypersonic flows, including chemical and thermal nonequilibrium. For the present study. LAURA was exercised for a perfect gas. The approximate run time for the LAURA code using a grid of $70 \times 81 \times 145$ on the Cray-2 computer is $50 \mathrm{~h}$ for this configuration. With an increase in grid to $81 \times 81 \times 145$, the approximate run time is $60 \mathrm{~h}$.

\section{Results and Discussion}

Because of the large number of data obtained for the modified orbiter model in the two lacilities, it is not possible to present all of the dati in the limited space of this report. Thus, sample heating-rate distributions measured along the windward centerline and across the span are presented herein.

The modified orbiter was tested over a range of angles of attack at both Mach 6 and Mach 10 in air, and over a wide range of Reynolds numbers, corresponding to laminar, transitional, and turbulent heating-rate measurements, at Mach 6 . Results were obtained at one value of Reynolds number at Mach 10 and correspond to laminar heating rates. The thermographic phosphor technique was used to augment quantitative measurements at Mach 10. Data illustrating the effects of angle of attack and Reynolds number at Mach 6 were obtained with the slotted ceramic model. Data illustrating the effects of Mach number and angle of attack at Mach 10 were obtained with the slotted stainless-steel model, since this was the only model tested at Mach 10. At low Reynolds numbers and Mach 6, corresponding 10 a laminar boundary layer, differences between measured heating distributions using the two different models were negligible.

\section{Effect of Angle of Attack}

Ghobul Surface-Temperature Mappings:

Global surface-temperature mappings of the windward surface of the modified orbiter at Mach 10 and $R e_{\infty, L}=4.2 \times 10^{5}$ are presented in Fig. 5 for $\alpha=15,20,30$, and 40 deg. These mappings were obtained using the relative-intensity, two-color thermographic phosphor technique. The data presented correspond to the time of arrival of the model at the nozzle centerline, which required approximately $0.5 \mathrm{~s}$. For consistency, the same color temperature scale 50) $\mathrm{F} \leq T \leq 280 \mathrm{~F}$ was used for all angles of atlack. (lt should be noted that the temperature range for the thermographic phosphor used in this study is $75 \mathrm{~F} \leq T \leq 340 \mathrm{~F}$.)

As expected, the windward surface temperature increases with increasing $\alpha$. Temperatures in the nose region and wing leading edge are observed to exceed the upper limit of the chosen colortemperature scale. However, for the regions of interest, namely, spanwise locations (i.e., wings), the selected temperature scale is quite adequate.

Traversing the configuration in a spanwise direction from the centerline at approximately three-quarters of the model length for $\alpha=15$ and $20 \mathrm{deg}$ (Figs. 5a and 5b) reveals two distinct striations in temperature. The most inboard streak is the result of the downstream elfects of the compression brought about by the discontinuous planform shape. As a result of this leading-edge compression, a stagnated region is produced, which spills over onto the windward surface (as a result of the highly complex three-dimensional flow field), causing a local enhancement in the heating over the windward surface. The outhoard striation pattern is the result of the interaction of the bow shock with the wing shock.

Further, density contours of the flowfield, obtained from an inviscid LAURA solution (taken from Ref. 25) and reproduced in Fig. 6 , illustrate the complex nature of the flowficld in the vicinity of the wing. As observed in Fig. 6, the slart of the wing shock occurs at $x / L \approx 0.7$. and the downstream effect of this compression produces an ahrupt increase in the local surface temperature (see Fig. 5). likewise. the interaction of the bow shock with the wing shock

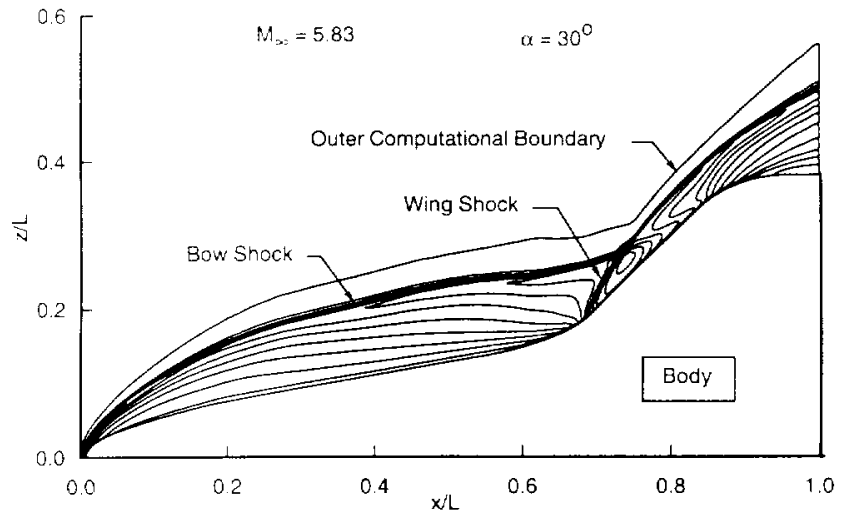

Fig. 6 Density contours in plane near leading edge (taken from Ref. 25).

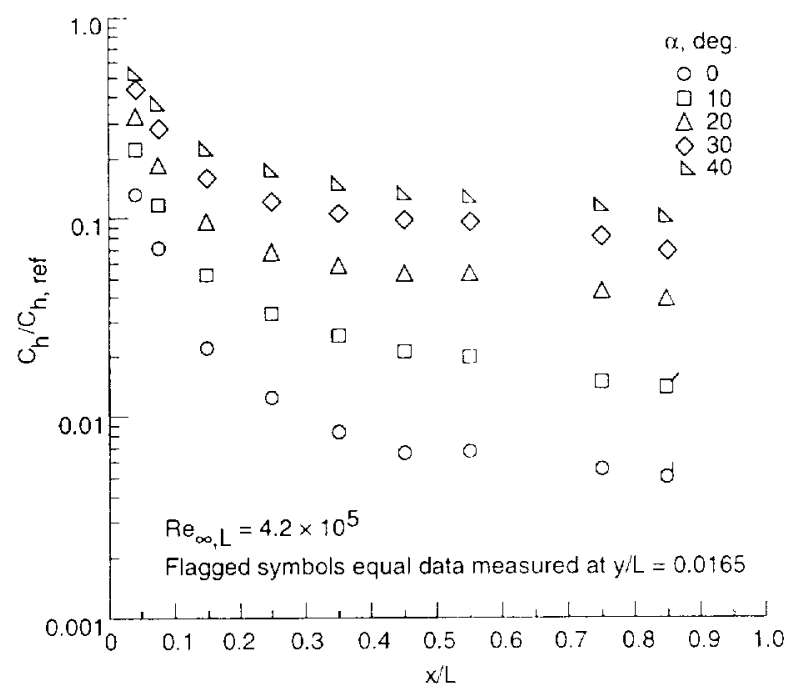

a) Mach 6

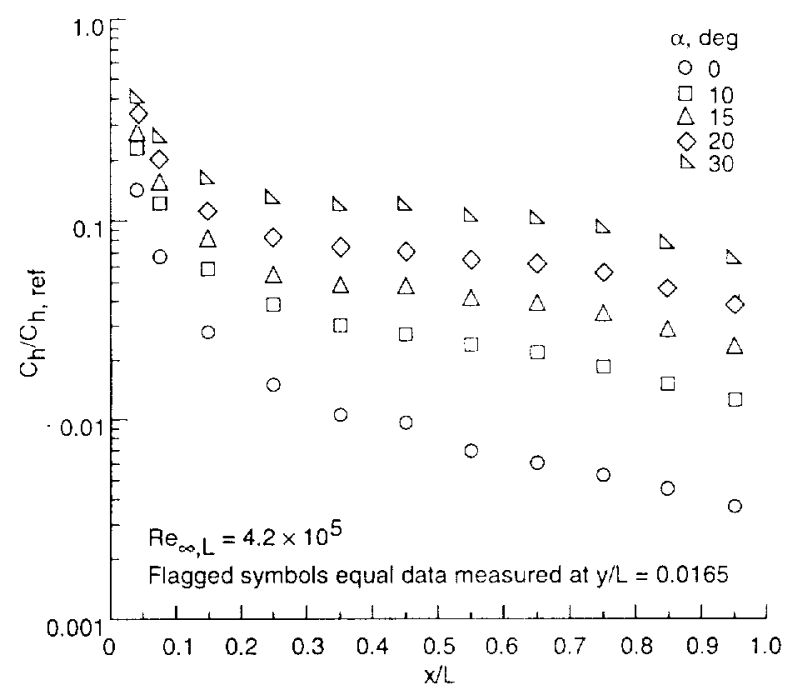

b) Mach 10

Fig. 7 Effect of angle of attack on windward centerline $(y / L=0.0)$ heating distributions.

$(x / L \approx 0.75$ in Fig. 6 ) generates a similar increase in local surface temperature and hence local heating (to be discussed subsequently), as noted in Fig. 5. These locally enhanced heating phenomena have been observed from entry heat-transfer data for the orbiter wing lower surface ${ }^{30,31}$ and from wind-tunnel tests of 0.0175 - and 0.01 scale models of the orbiter at Mach 6, 8, and 10 using the phasechange paint technique. ${ }^{32,33}$ As $\alpha$ is increased to $30 \mathrm{deg}$, the local enhancements in windward heating are still discernable, although 
not as distinct. With a further increase in $\alpha$ to $40 \mathrm{deg}$, these streaks appear to vanish.

\section{Longitudinal Heat-Transfer Distributions}

Measured heating distributions along the windward centerline of the modified orbiter using the thin-film gauge technique are presented in Fig. 7 for Mach numbers of 6 and 10 and for a freestream Reynolds number based on length, $R e_{\infty}, L$, of $4.2 \times 10^{5}$. The variation of heat-transfer coefficient ratio, $C_{h} / C_{h}$,ref, with wetted length $x / L$ is presented for a range of angles of attack. At this Reynolds number, the flow along the windward symmetry plane is well behaved and is indicative of a laminar boundary layer. As expected, the heat-transfer coefficient ratio increases with increasing angle of attack. In general, increasing $\alpha$ from 0 to $10 \mathrm{deg}$ produces an increase in heating of approximately a factor of 3 , whereas this same 10 -deg increase in $\alpha$ from 30 to 40 deg produces a much smaller increase of about $40 \%$ along the body.

Spanwise Heat-Transfer Distributions

Spanwise distributions of $C_{h} / C_{h}$ ref on the wing lower surface for a range of angles of attack are presented for $x / L$ values of 0.75 and 0.85 at Mach 6 and 10, in Figs. 8 and 9, respectively. These data correspond to $R e_{\infty, L}=4.2 \times 10^{5}$. For both Mach numbers and values of $x / L$, trends in spanwise heating vary appreciably with increasing $\alpha$, indicating significant changes in the flowfield.

For $\alpha<20 \mathrm{deg}, C_{h} / C_{h \text {,ref }}$ increases immediately from the centerline in the direction of the wing leading edge $(y / L \approx 0.25)$ for both

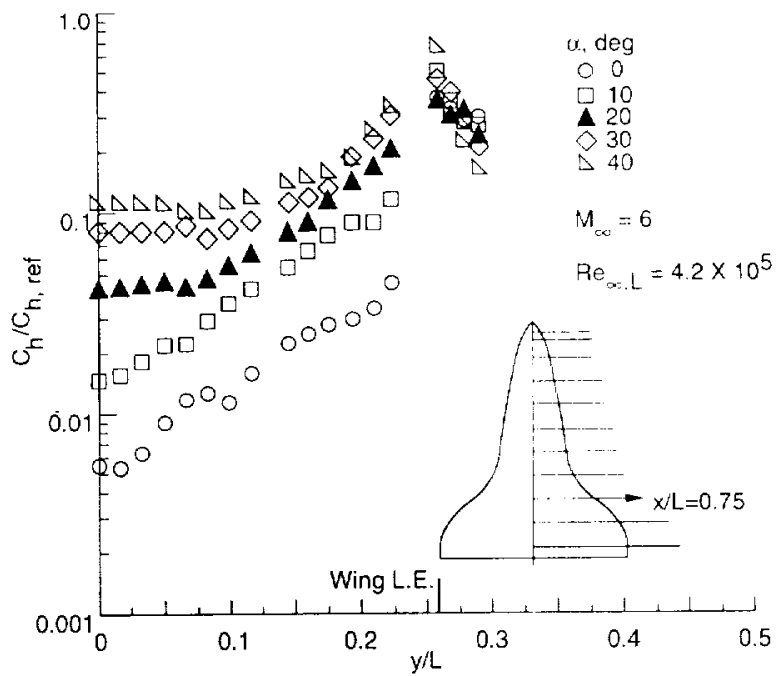

a) $x / L=0.75$

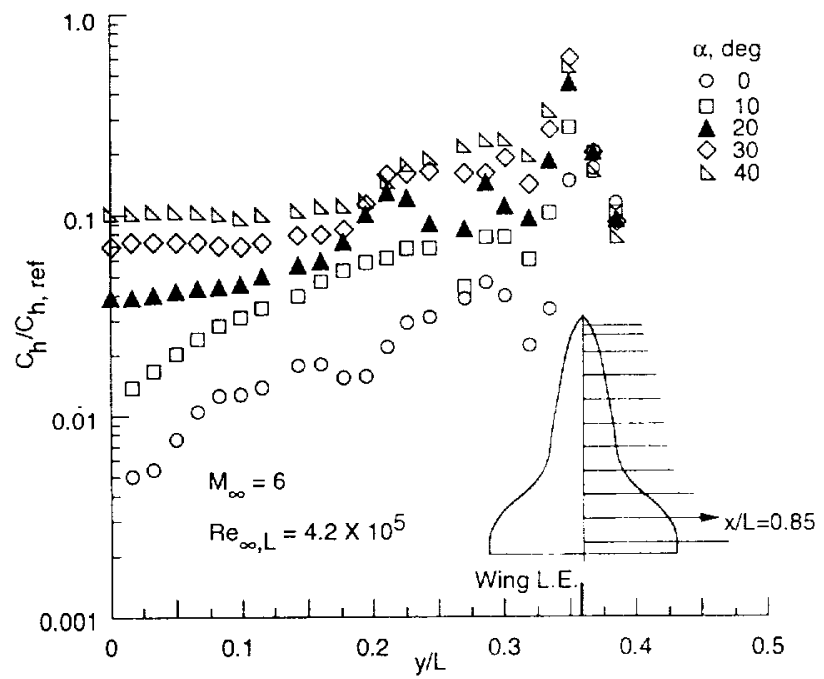

b) $x / L=0.85$

Fig. 8 Effect of angle of attack on spanwise distributions of heattransfer coefficient ratio (solid symbols for $\alpha=20 \mathrm{deg}$ shown for clarity).
Mach 6 and Mach 10. For these lower angles of attack, a two-orderof-magnitude increase in $C_{h} / C_{h \text { ref }}$ occurs between the centerline and the wing leading edge. One possible explanation for this pronounced increase in heat-transfer coefficient ratio in the spanwise direction is the inboard flow caused by the increase in pressure along the wing leading edge and planform discontinuity (i.e., discontinuity in planform shape caused by the junction of the double delta wing)

For $\alpha \geq 20 \mathrm{deg}$, a nearly constant (i.e., more 2-D-like) heattransfer coefficient ratio is observed for $y / L \leq 0.1$. For $y / L>0.1$, $C_{h} / C_{h \text {,ref }}$ increases in the direction of the wing leading edge. At these conditions, the flow along the symmetry plane exhibits parallel streamlines (to be discussed subsequently); that is, increasing angle of attack serves to increase the pressure along the windward centerline, thus "straightening" the local flow. (It should be noted that according to the predictions of Weilmuenster, ${ }^{23}$ the majority of the flowfield over the windward surface is supersonic for $\alpha \leq 30$ deg with the exception of a small subsonic pocket near the nose of the vehicle. However, for $\alpha>30 \mathrm{deg}$, the flow is characterized by a large embedded subsonic region.)

With increasing angle of attack, the difference in $C_{h} / C_{h, \text { rel }}$ measured at the centerline and at the wing leading edge decreases. For example, at $\alpha=0 \mathrm{deg}$, there is approximately a two-order-ofmagnitude increase in heating between the centerline and the wing leading edge ( $y / L \approx 0.25$ ). However, at $\alpha=40 \mathrm{deg}$, there is less than an order-of-magnitude increase in heating as measured at these two points.

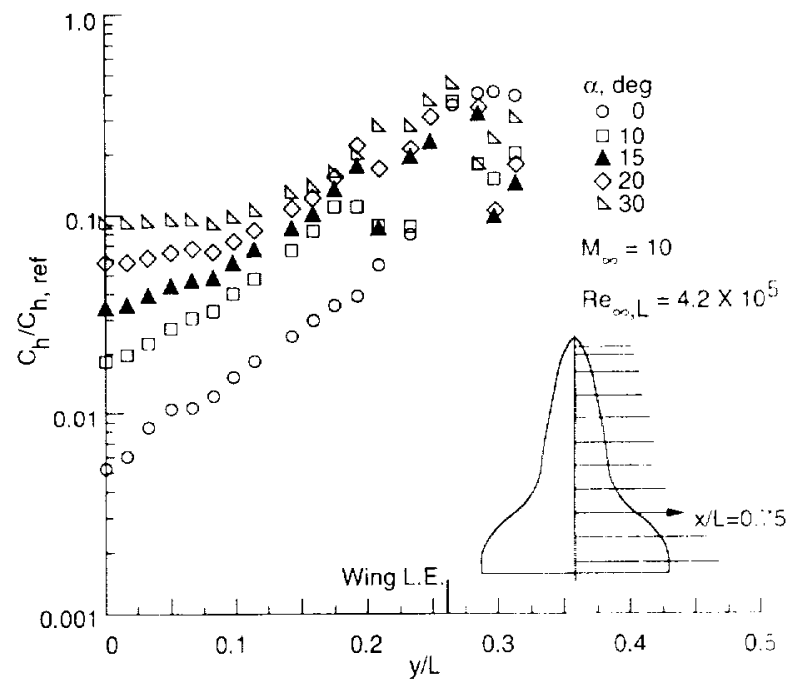

a) $x / L=0.75$

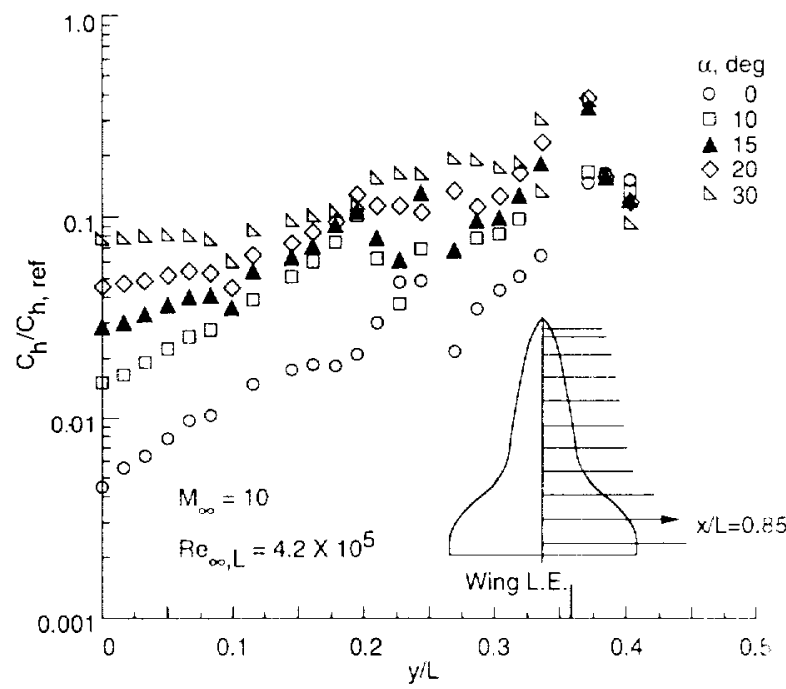

b) $x / L=0.85$

Fig. 9 Effect of angle of attack on spanwise distributions of heattransfer coefficient ratio (solid symbols for $\alpha=15$ deg shown for clarity). 
At Mach 10 (Fig. 9a), a local increase in heating is observed around $y / L \approx 0.17$ to 0.20 and $x / L=0.75$ for $\alpha \geq 10 \mathrm{deg}$. At $\alpha=30 \mathrm{deg}$, the local increase in $C_{h} / C_{h \text {,ref }}$ is still evident but not as distinct as for $\alpha<30 \mathrm{deg}$. (Thermal mapping is presented in Fig. 5c.) This discontinuity in spanwise heating trend is the result of increased pressure brought about by the discontinuous planform caused by the double delta wing and is discussed in the previous section entitled Global Surface Temperature Mappings; similar results are noted for $x / L=0.85$ (Fig. 9b).

Returning to the Mach 6 results of Fig. $8 \mathrm{~b}$, along with the first abrupt increase in $C_{h} / C_{h \text {,ref }}$ identified at $y / L \approx 0.2$ and $\alpha \geq 20 \mathrm{deg}$ and discussed previously, a second well-defined discontinuity in the trend of the heat-transfer coefficient ratio occurs at $y / L \approx 0.30$ for $\alpha \geq 0$ deg. For Mach 10 (Fig. 9b), this discontinuity occurs for $\alpha \geq 0$ deg and $y / L \approx 0.28$. For both Mach numbers, as $\alpha$ is increased to 30 deg or greater, this local increase in $C_{h} / C_{h \text {,rel }}$ along $x / L=0.85$ is still visible. but not as pronounced. This region of locally enhanced heating is the result of the interaction of the bow shock with the wing shock. The use of closely spaced thin-film gauges allows sufficient spatial resolution to acquire discrete quantitative measurements indicating the magnitude of the streak-heating phenomena.

\section{Reynolds-Number Effects}

Lonsitudinal Heat-Transfer Distributions.

The effect of Reynolds number on centerline heat-transfer distributions at Mach 6 is presented in Fig. 10 for a range of Reynolds

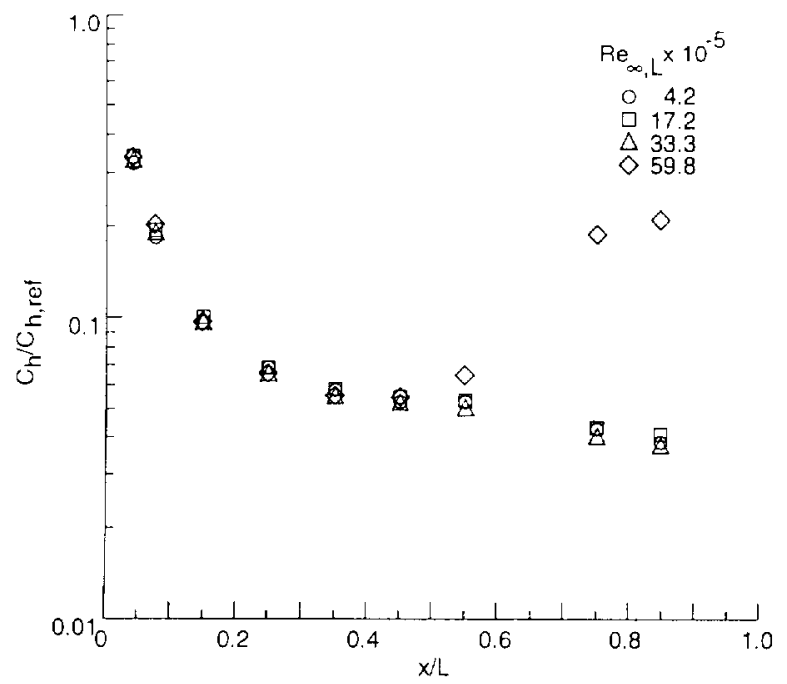

a) $\alpha=20 \mathrm{deg}$

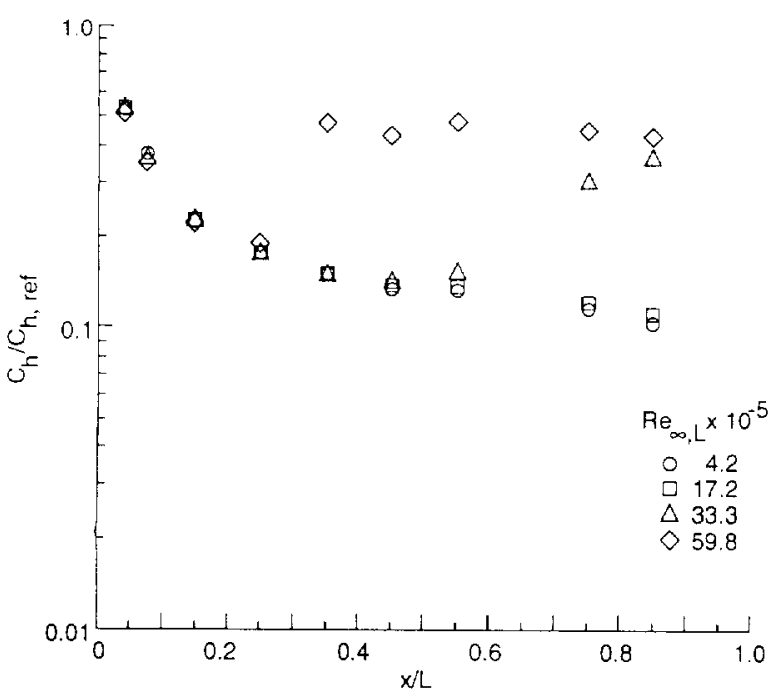

b) $\alpha=40 \mathrm{deg}$

Fig. 10 Effect of Reynolds number on longitudinal $(y / L=0.0)$ distributions of heat-transfer coefficient ratio at $M_{\infty}=6$. number from $4.2 \times 10^{5}$ to $59.8 \times 10^{5}$ and at angles of attack of 20 and $40 \mathrm{deg}$. Differences between the measured data for the laminar cases $\left[R e_{\infty, L} \leq 33.3 \times 10^{5}\right.$ for $\alpha=20 \mathrm{deg}$ (Fig. 10a) and $R e_{\infty, L} \leq 17.2 \times 10^{5}$ for $\alpha=40 \mathrm{deg}$ (Fig. 10b)] are essentially negligible. (The effect of Reynolds number on laminar centerline heattransfer coefficient ratio has been shown in Ref. 18 to decrease with increasing angle of attack for $15 \mathrm{deg} \leq \alpha \leq 45 \mathrm{deg}$, corresponding to decreasing viscous effects.) Boundary-layer transition is observed to occur along the windward centerline around $x / L \approx 0.55$ for $R e_{\infty, L}=59.8 \times 10^{5}$ and $\alpha=20 \mathrm{deg}$ and for $R e_{\infty, L}=33.3 \times 10^{5}$ for $\alpha=40 \mathrm{deg}$. For the highest Reynolds number and $\alpha=40 \mathrm{deg}$, the transition location has moved upstream toward the nose and is located around $x / L \simeq 0.25$. The distribution of $C_{h} / C_{h, \text { rrf }}$ following this transition region is indicative of a fully turbulent boundary layer. At $\alpha=40 \mathrm{deg}$, the heating level for the highest- $R e_{\infty, L}$ case (turbulent boundary layer) at $x / L \approx 0.75$ is about 5 times the laminar value. The value of turbulent heat-transfer coefficient at this location $(x / L=0.75)$ is very close to the value measured in the nose region (i.e., $x / L=0.075$ ).

Spanwise Heat-Transfer Distributions

The effect of Reynolds number along rays normal to the centerline for a range of Reynolds numbers and $\alpha=20$ and $40 \mathrm{deg}$ at three longitudinal locations $(x / L=0.35,0.75$, and 0.85$)$ is presented in Figs. 11 and 12 . For $x / L=0.35$ (upstream of the planform discontinuity) and $\alpha=20 \mathrm{deg}$ (Fig. 11 a), $C_{h} / C_{h \text {, ref }}$ distributions are indicative of a laminar boundary layer for all values of Reynolds number, with essentially no effect of Reynolds number on spanwise heating. At a longitudinal station of 0.75 (i.e., downstream of the planform discontinuity) and $\alpha=20 \mathrm{deg}$ (Fig. 1 l b), heat-transfer coefficient distributions indicative of a laminar boundary layer are observed for $R e_{\infty, L} \leq 33.3 \times 10^{5}$ but not at the highest value of $R e_{\infty, L}$. Traversing across the span for $R e_{\infty, L}=59.8 \times 10^{5}$, the value of $C_{h} / C_{h \text {,ref }}$ at the centerline is indicative of a nonlaminar boundary layer followed by a return to laminar heat-transfer coefficient ratios prior to an abrupt discontinuity in the heating trend occurring at $y / L \approx 0.20$. The location $(y / L \approx 0.20$ for $\alpha=20$ deg and $R e_{\infty, L}=59.8 \times 10^{6}$ ) of this discontinuity in $C_{h} / C_{h \text {,ref }}$ corresponds to the local downstream effects of the increased heating along the planform leading edge coinciding with the region of flow compression at the junction of the double delta wings.

Continuing to the next longitudinal station at $x / L=0.85$ and $\alpha=20 \mathrm{deg}$ (Fig. 11c), laminar heat-transfer coefficient ratios are observed adjacent to the windward centerline (i.e., $y / L \leq 0.17$ ) for $R e_{\infty L} \leq 33.3 \times 10^{5}$, and evidence of local enhanced heating is observed for $y / L$ locations of approximately 0.2 and 0.3 . These abrupt increases in $C_{h} / C_{h \text {,ref }}$ have been cited previously as local downstream effects of increased heating along the wing leading edge, resulting from flow compression at the junction caused by the double delta wings $(y / L \approx 0.20)$ and the bow-shock-wingshock interaction $(y / L=0.3)$. However, for $R e_{x, L} \geq 33.3 \times 10^{5}$, the two distinct striations in heating may, in addition to the causes outlined above, be catalyst to local transition. At the wing leading edge and up onto the leeward surface, the effect of Reynolds number is essentially negligible for the laminar distributions.

As $R e_{\infty . L}$ is increased above $33.3 \times 10^{5}$, flow along the centerline $(y / L=0)$ is nonlaminar (probably transitional; see Fig. 10a) and then laminar again for $0.05<y / L<0.15$ away from the centerline, but then becomes transitional again at $x / L \approx 0.17$. The flow again exhibits nonlaminar trends in $C_{h} / C_{h}$ ref, which are indicative of a fully turbulent boundary layer to the planform leading edge. These trends in spanwise heating were repeatable. The behavior of the flow along the span indicates that transition begins in regions or pockets.

As discussed in Ref. 22, the manner in which transition occurs depends on the history of the streamlines producing the effect. For this reason, transitional and even turbulent flow could occur for one set of streamlines while the adjacent set of streamlines remained laminar. Qualitatively, this can be seen from the predicted inviscid surface streamline pattern shown for $M_{\infty}=9.15$ and $\alpha=34.8 \mathrm{deg}$ in the flight case in Fig. 13 (taken from Ref. 22). This flow behavior was also observed from other flight data ${ }^{30.31}$ (Fig. 14). For $\alpha=40$ deg and these same longitudinal locations (Fig. 12), similar heat- 


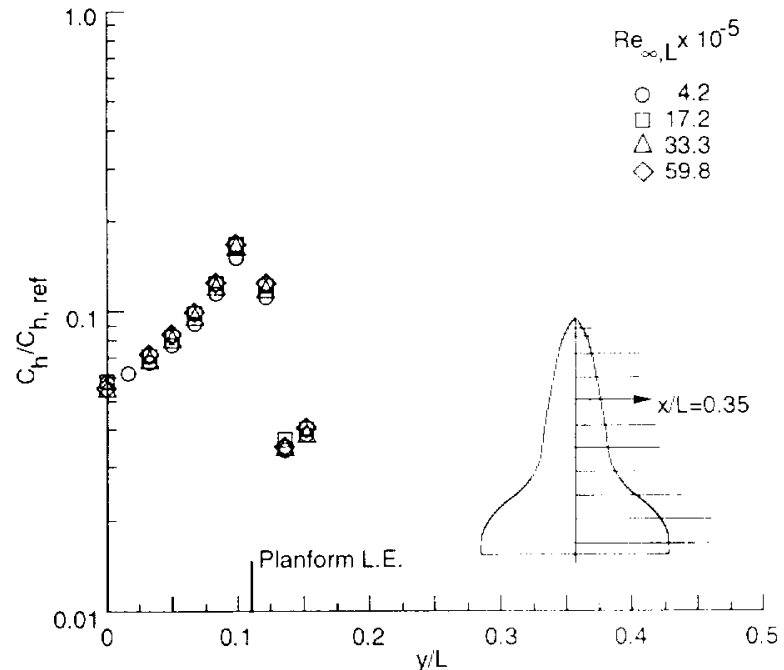

a) $x / L=0.35$

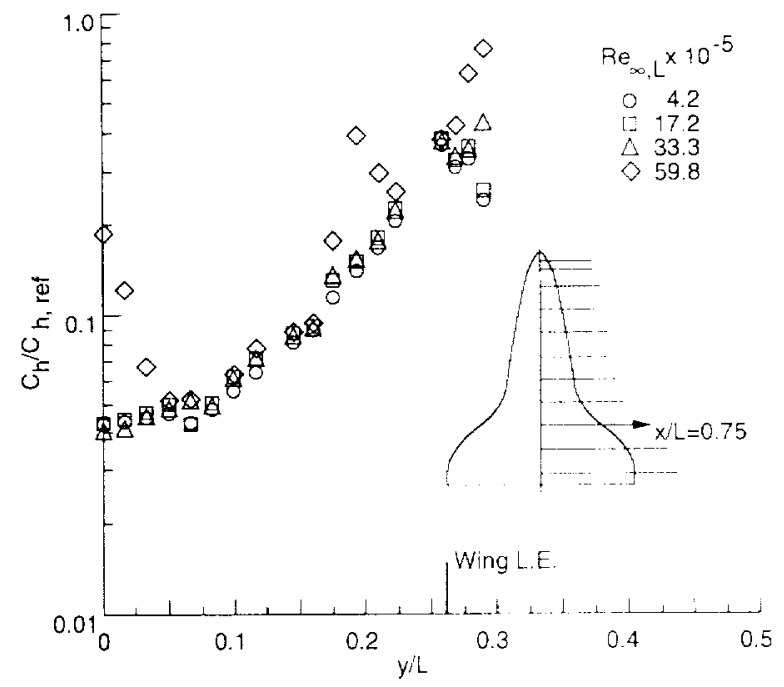

b) $x / L=0.75$

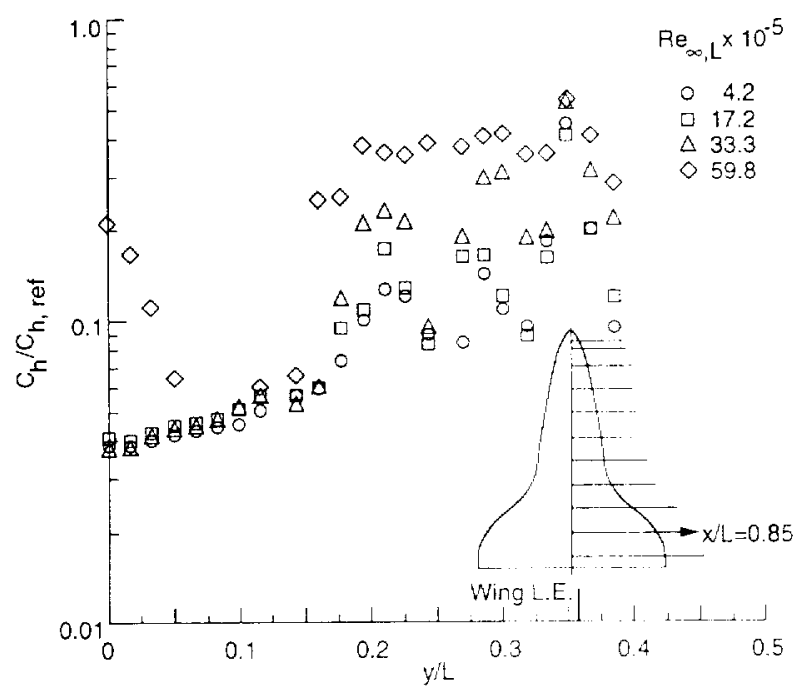

c) $x / L=0.85$

Fig. 11 Effect of Reynolds number on spanwise distributions of heattransfer coefficient ratio: $M_{\infty}=6 ; \alpha=20 \mathrm{deg}$.

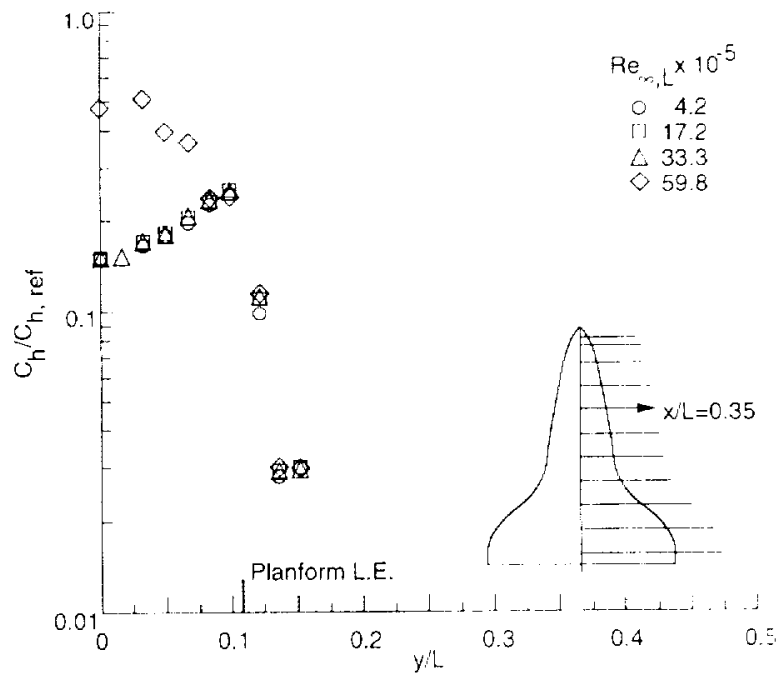

a) $x / L=0.35$

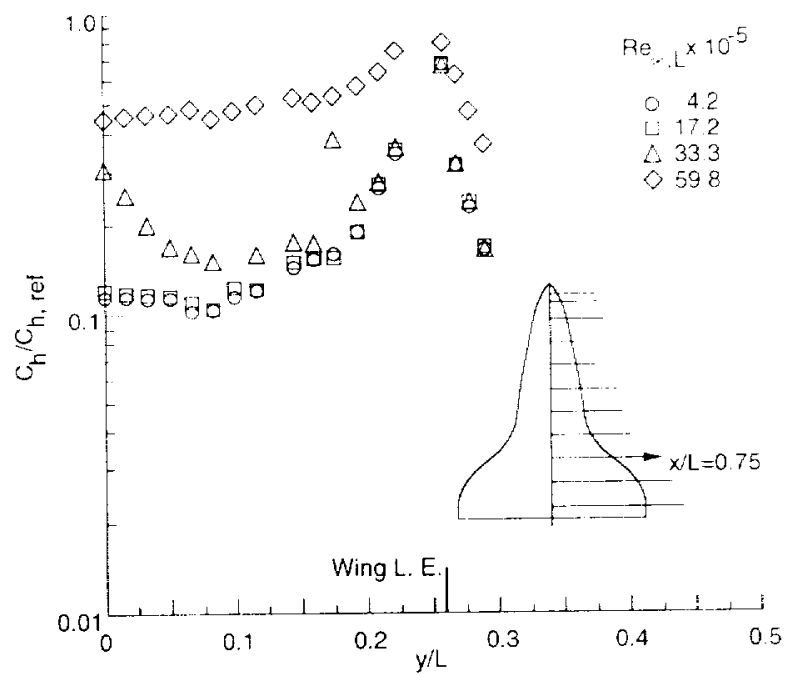

b) $x / L=0.75$

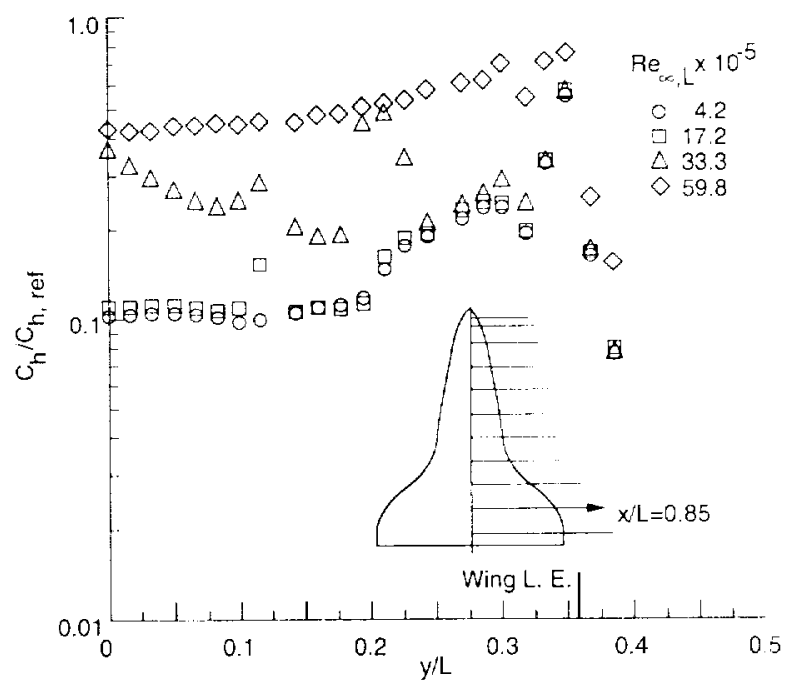

c) $x / L=0.85$

Fig. 12 Effect of Reynolds number on spanwise distributions of heattransfer coefficient ratio at Mach 6 and $\alpha=40 \mathrm{deg}$. 


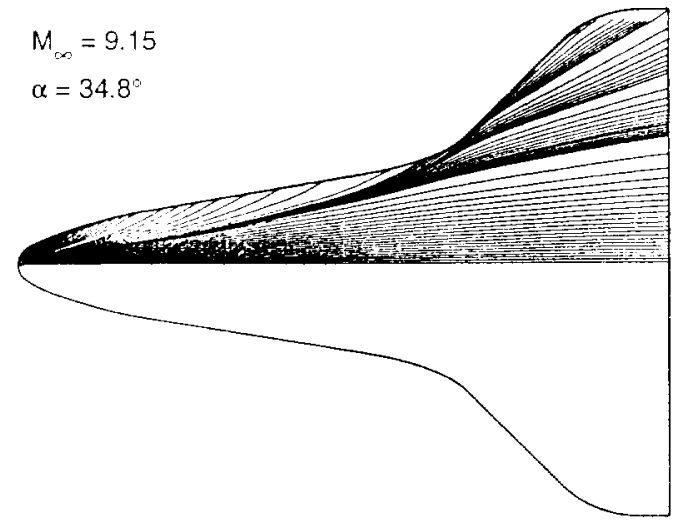

Fig. 1.3 Computed surface streamline pattern on full-scale Shuttle Orbiter (taken from Ref. 22 ).

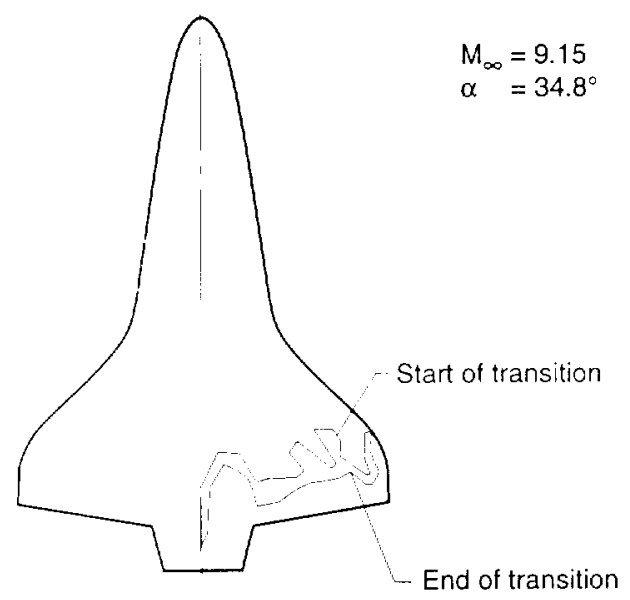

Fig. 14 Transition front on Shuttle Orbiter wing from STS-2 flight (taken from Ref. 31).

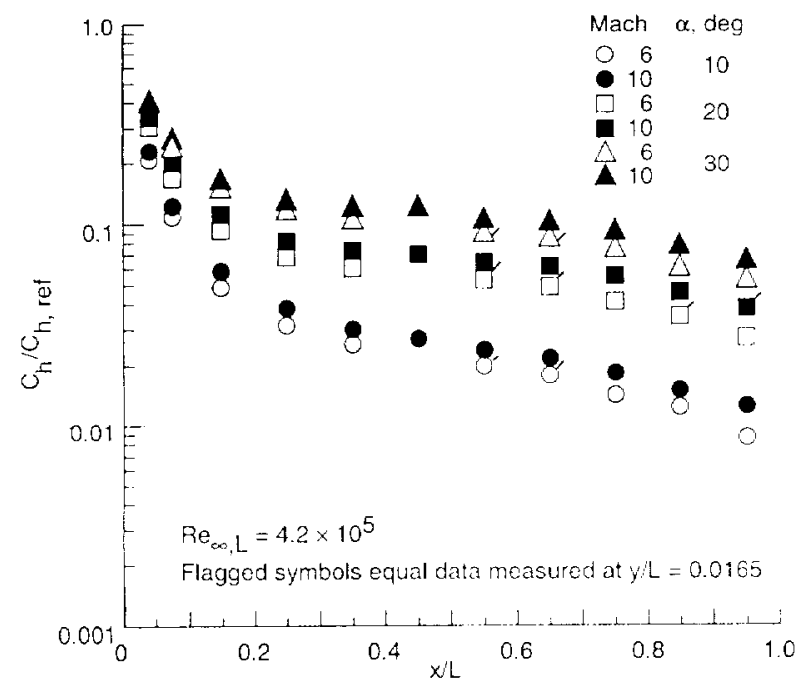

Fig, 15 Effect of Mach number on longitudinal $(y / L=0.0)$ distributions of heat-transfer coefficient ratio.

ing trends are observed. although transition to a turbulent boundary laver is noted to occur at lower values of $R e_{x} L$ than for $\alpha=20 \mathrm{deg}$. For this angle of attack and $R e^{\prime}, L \leq 17.2 \times 10^{5}$, the distributions of the heat-transfer coefficient ratio are well behaved and heating trends indicative of a laminar boundary layer are noted. As $R e_{\chi, L}$ is increased to $33.3 \times 10^{5}$, the $C_{h} / C_{h \text {.ret }}$ distributions at $x / L=0.75$ and 0.85 become nonlaminar (transitional) at the centerline. with a general tendency to return to values characteristic of a laminar houndary layer in the spanwise direction (i.e.. increasing $y / L$ ). For

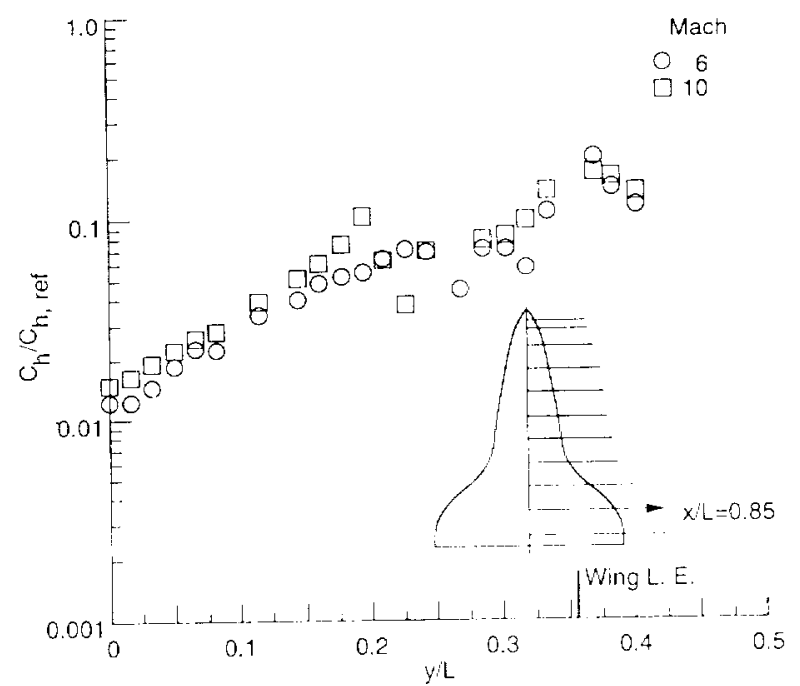

a) $\alpha=10 \mathrm{deg}$

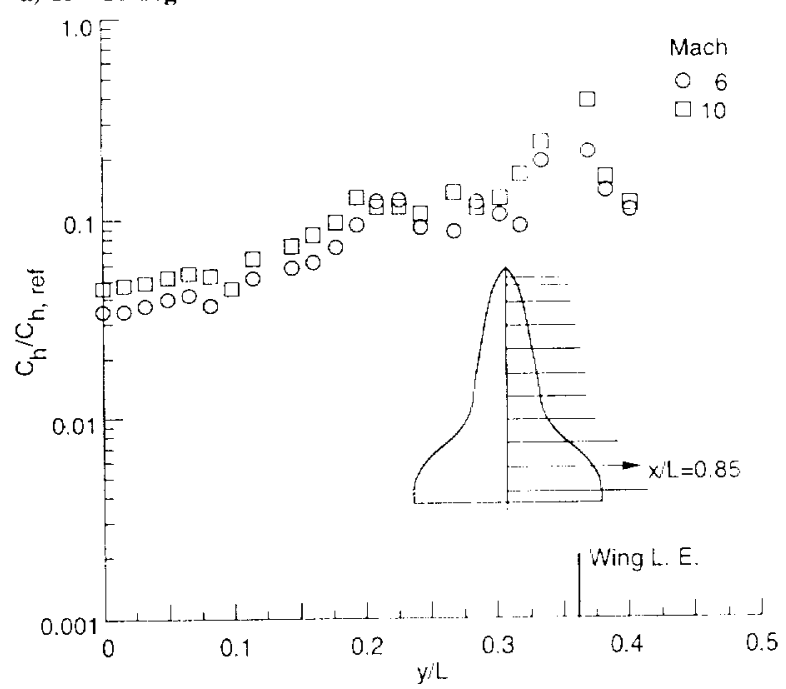

b) $\alpha=20 \mathrm{deg}$

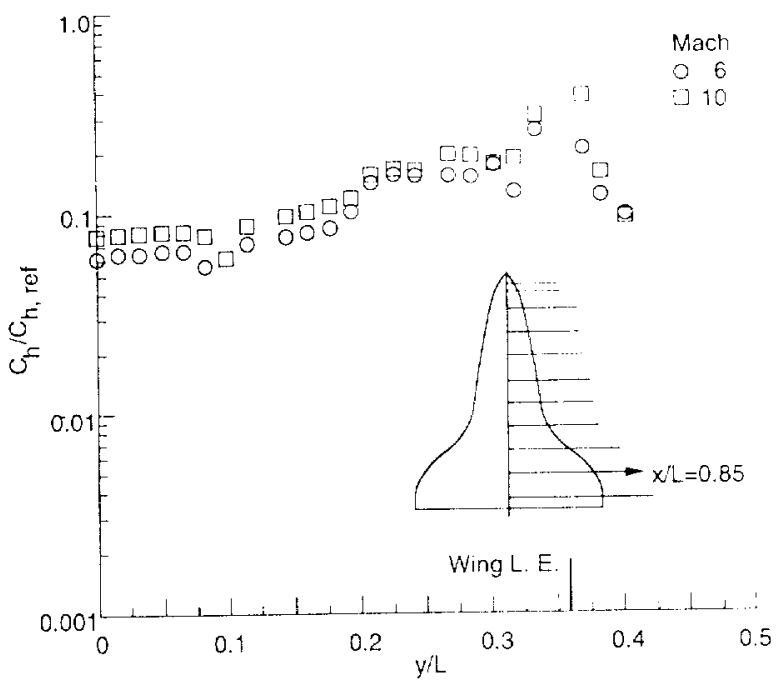

c) $\alpha=30 \mathrm{deg}$

Fig. 16 Effect of Mach number on spanwise distribution of heattransfer coefficient ratio at $x / L=0.85$ and $R e_{\infty, L}=4.2 \times 10^{5}$.

$R e_{x, L}=59.8 \times 10^{5}$, the distributions imply a fully turbulent houndary layer with heat-transfer coefficient ratios approximately 4 to 5 times their laminar counterparts.

Effect of Mach Number

Longirudinal Heat-Trunsfer Distributions

The effect of Mach number on centerline nondimensional heattransfer coefficient distributions at angles of attack of 10.20 , and 


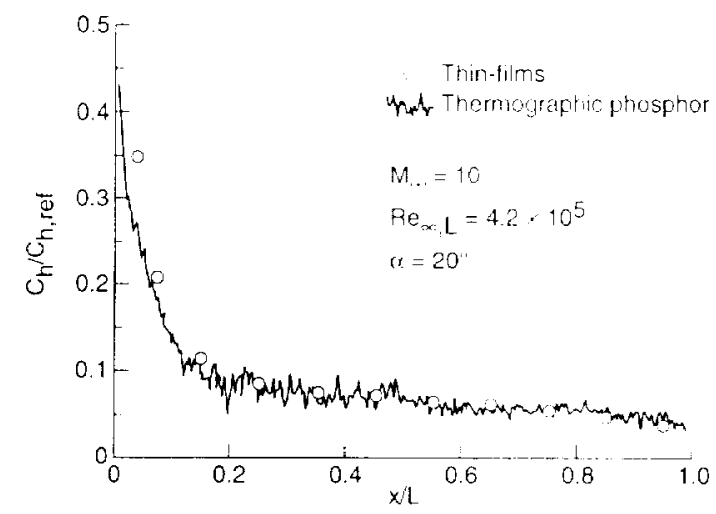

Fig. 17 Comparisons of windward centerline $(y / L=0.0)$ distributions of heat-transfer coefficient ratio obtained with thermographic phosphors and thin-film gauge techniques.

$30 \mathrm{deg}$ is presented in Fig. 15. These data correspond to $R e_{x, L}=$ $4.2 \times 10^{5}$ and thus to laminar heating distributions. For the highest angle of attack investigated, the Mach $10 C_{h} / C_{h, \text { ref }}$ distributions are slightly higher than those for Mach 6 (approximately 5 to $8 \%$ near the trailing edge of the body). One possible contributor to this increase in heating with Mach number is the corresponding increase in boundary-layer displacement thickness, leading to a more blunt effective aeroline. Similar results are noted for $\alpha=10$ and $20 \mathrm{deg}$, with the difference between measurements at Mach 6 and 10 increasing slightly with decreasing $\alpha$. Also, it should be noted that although the Reynolds number is matched closely between Mach 6 and 10 , the ratio of wall temperature to total temperature is not; $T_{t 1} / T_{t, 2}$ is approximately 0.3 at Mach 10 and 0.6 at Mach 6 . The lower value of $T_{10} / T_{12}$ (i.e.. colder wall) at Mach 10 may also contribute to the observed increase in heating with increasing Mach number.

Spannise Heat-Transfer Distribution

The effect of Mach number on a spanwise distribution corresponding to a location $x / L$ of 0.85 is presented in Fig. 16. Data are presented for $\alpha=10,20$, and 30 deg at $R e_{\alpha} .=4.2 \times 10^{5}$. Again, on the centerline $(y / L=0.0)$ the Mach 10 data exceed the Mach 6 data by approximately 5 to $8 \%$. This is also the case for $0 \leq y / L \leq 0.20$. Beginning at $y / L \approx 0.20$ and continuing to the planform leading edge $(y / L \approx 0.36)$, differences in location of enhanced heating produced by the leading-edge compression at the planform discontinuity and the local enhanced heating produced by the bow-shock-wing-shock interaction are observed. For example, at $\alpha=20 \mathrm{deg}$ (Fig. 16b), where these llowtield characteristics are most prominent (see section entitled Global Surface-Temperature Mappings), the locations of these enhancements move farther inboard with increasing Mach number. At Mach 6, peaks in spanwise heating occur at approximately 0.22 and 0.30 , whereas at Mach 10) they occur at 0.20 and 0.26 . This is expected and is a result of changes in shock structure (i.e., turning angles) with increasing Mach number.

\section{Comparisons with Two-Color Thermographic}

Phosphor Technique

Lomgitudinal Heat-Transfer Distributions

Comparisons of surface heating distributions measured along the windward centerline using the thin-film gauge technique and the relative-intensity two-color thermographic phosphor technique are presented in Fig. 17. These data correspond to Mach 10, Re $e_{\text {..t. }}$ $=4.2 \times 10^{5}$, and an angle of attack of $20 \mathrm{deg}$. For this laminar flow condition, agreement between the two lechniques is quite good, the maximum difference being less than $15 \%$. The present comparisons are the first between the Langley standard for quantitative heattransfer measurements (thin-film gauges) and the newly developed phosphor system. ${ }^{10 \cdot 12}$

\section{Spannise Heat-Transfer Distributions}

Comparisons of spanwise heating distributions between the two measurement techniques are presented in Fig. 18 for $\alpha=20$ deg and $x / L$ values of $0.65,0.75$, and 0.85 . These data correspond to
$R e_{x, 1}=4.2 \times 10^{5}$. Again, the two techniques agree to within $15 \%$. It should be noted that the locations of the thin-film gauges are described in terms of a wetted-surface distance, whereas the thermographic phosphor technique uses a projected 2-D image of the windward planform. Thus, spatial differences exist between the two techniques, with the worst case occurring near the outboard wing section. At present the determination of exact longitudinal locations for spanwise comparisons is somewhat difficult and increases the inaceuracy. ${ }^{10-12}$ The global information acquired using this technique is also an extremely important tool for deducing the complex 3-D flowfield effects on surface characteristics. Since models cast for the thermographic phosphor technique are orders of magnilude less expensive than those fabricated for use with the thin-film gauge technique and require significantly less time for fabricalion, the thermographic phosphor technique is a very attractive means of obtaining near-quantitative global heat-transfer information in a rapid manner.

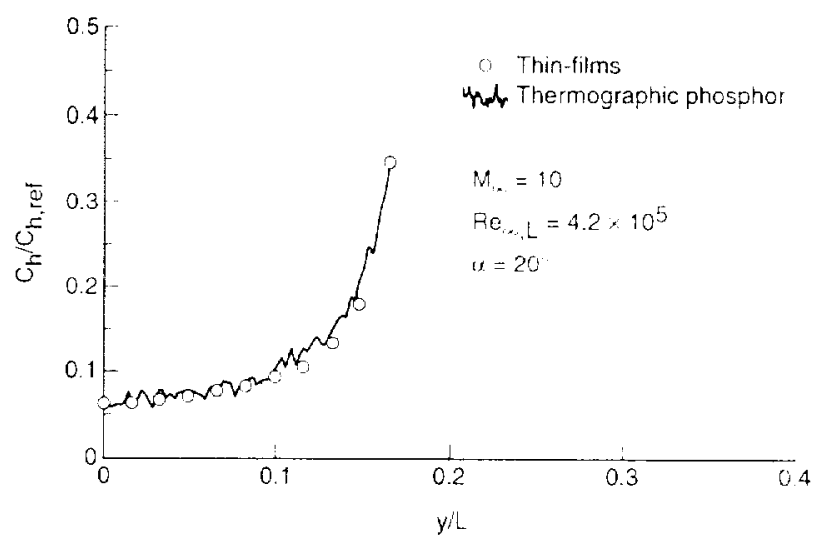

a) $x / L=0.65$

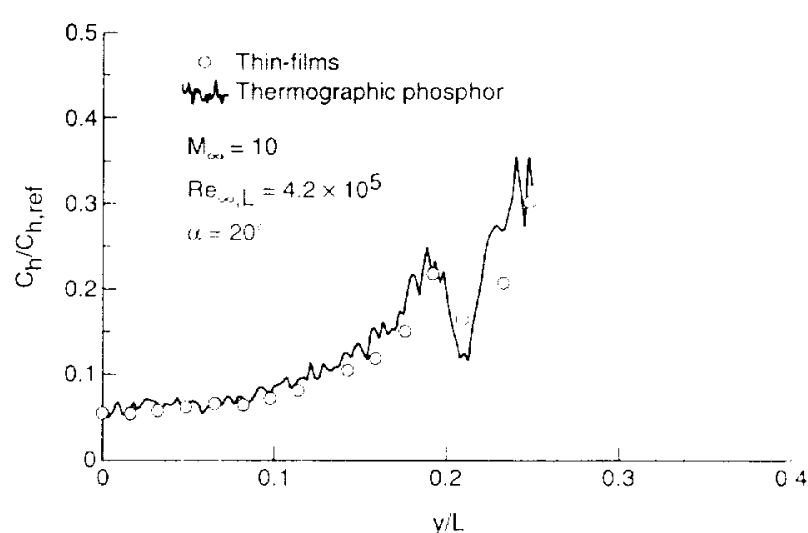

b) $x / L=0.75$

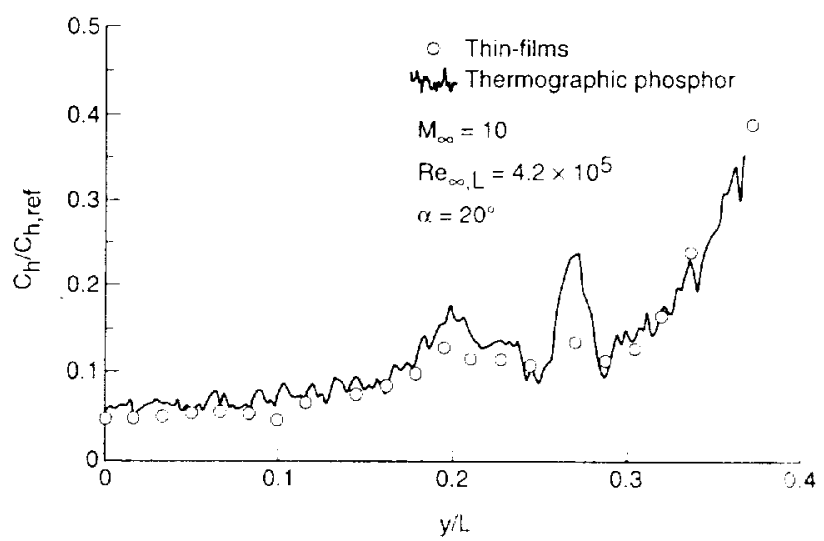

c) $x / L=0.85$

Fig. 18 Comparisons of spanwise distributions of heat-transfer coefficient ratio obtained with thermographic phosphors and thin-film gauge techniques. 


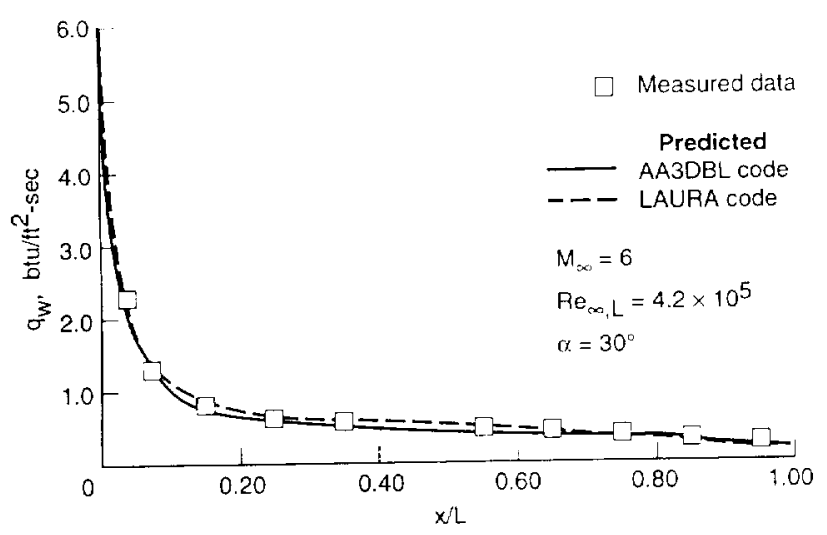

Fig. 19 Comparison of measured and predicted heat-transfer rate distributions along windward centerline $(y / L=0.0)$.

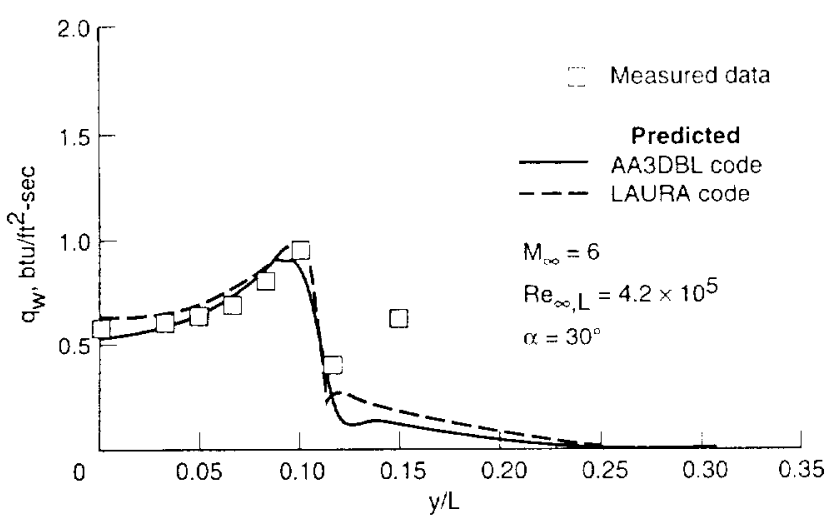

a) $x / L=0.35$

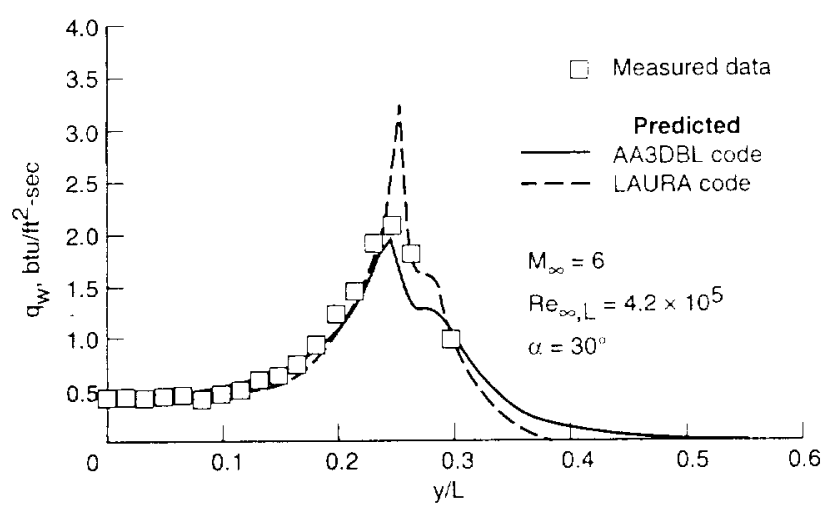

b) $x / L=0.75$

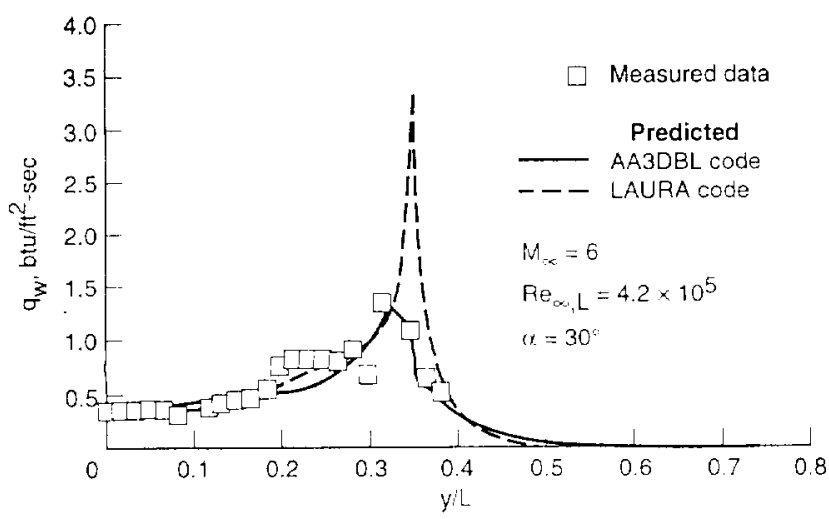

c) $x / L=0.85$

Fig. 20 Comparison of measured and predicted spanwise heattransfer rate distributions.
Comparisons with Prediction

Longitudinal Heat-Transfer Distributions

Sample comparisons of measured and predicted heating distributions are presented in this section for a Mach number approximately equal to 6 and $R e_{x, L} \approx 4.2 \times 10^{5}$. A more complete set of theoretical comparisons with the present experimental data set for angles of attack of 30 and $40 \mathrm{deg}$ are presented in Ref. 25. Values of the heat-transfer rate $q$ corresponding to a wall temperature of $540 \mathrm{R}$ are used in these comparisons.

Comparisons of measured and predicted heating distributions along the centerline are presented in Fig. 19 for an angle of attack of $30 \mathrm{deg}$. For this laminar flow condition, the calculations are in very good agreement with measurement along the windward symmetry plane. Differences between the two computational methods and the experimental data are within approximately $10 \%$.

\section{Spanwise Heat-Trunsfer Distribution}

Comparisons of measured and predicted heat-transfer rate to the wing lower surface are presented in Figs. 20a, 20b, and 20c for longitudinal locations $x / L=0.35,0.75$, and 0.85 . respectively These data are for $\alpha=30 \mathrm{deg}$ and correspond to laminar healIransfer distributions. For $x / L=0.35$ and 0.75 , both the boundarylayer solver (AA3DBL) and the Navier-Stokes solver (LAURA) exhibit fairly good agreement with measurement over the wing and onto the leeward surface. For $x / L=0.85$. LAURA provides a better qualitative description of the heat-transfer distribution, which includes the abrupt increase in heat-transfer rate at $y / L \approx 0.20$. than does the AA3DBL code. In general, both codes predict the spanwise heating levels reasonably well.

\section{Concluding Remarks}

Detailed distributions of the laminar, transitional, and turbulent heat-transfer coefficient ratio were measured laterally at several longitudinal stations over the windward surface of a modified Space Shuttle Orbiter configuration in air at Mach 6 and 10 for a range of Reynolds numbers and angles of attack. Predictions from an approximate viscous method, AA3DBL, and a Navier-Stokes solver, LAURA, were compared with measured values in both longitudinal and spanwise directions

A significant increase in the measured heat-transfer coefficient ratio was observed with increasing angle of attack for both longitudinal and spanwise directions, as expected. For $\alpha \leq 10 \mathrm{deg}$, a twoorder-of-magnitude increase was noted between the heat-transfer coefficient ratio measured at the centerline and in the region of the wing leading edge; this measured difference decreased with increasing angle of attack. With an increase in Reynolds number. the laminar flow over the windward surface became turbulent, and measured heat-transfer coefficient ratios for the turbulent flow cases were about 5 times those for the laminar flow cases. Spanwise distributions indicate that transition occurs in regions or pockets; that is, for a particular longitudinal station the spanwise flow may he laminar and transitional combinations before becoming completely turbulent. Local enhancement regions in heating (i.e., striation or streak heating) over the wing were observed in spanwise distributions and are caused by wing leading-edge compression at the planform discontinuity producing a local stagnation region. which spills onto the wing lower surface, and by the interaction of the bow shock with the wing shock. The strength of each distinct striation pattern decreased with increasing angle of attack. Heat-transfer rates predicted with the AA3DBL and LAURA codes were generally in good agreement with measurement for both longitudinal and spanwise distributions.

\section{Acknowledgments}

The author wishes to acknowledge the contributions of N. R. Merski of the Langley Research Center's Aerothermodynamics Branch, Gas Dynamics Division, who provided the line analysis data from the thermographic phosphor technique; M. R. Fetty, Purdue University Engineering Co-op student, for her efforts in the data reduetion process; and H. H. Hamilton and F. A. Greene of the Langley Re search Center's Aerothermodynamics Branch, Gas Dynamics Division, who provided the predictions presented herein. 


\section{References}

${ }^{1}$ Hook, W. R., and Freeman, D. C., Jr., "Lifting-Body Option for a Space Station Rescue Vehicle," International Astronautical Federation, Paper 89 246. Oct. 1989.

2Piland, W. M., and Talay, T. A., "Advanced Manned Launch System Comparisons," International Astronautical Federation, Paper 89-221, Oct. 1989.

${ }^{3}$ Piland, W. M., Talay, T. A., and Stone, H. W., "Personnel Launch-System Definition," International Astronautical Federation, Paper $90-160$, Oct. 1990.

${ }^{4}$ Stanley, D. O., Talay, T. A., Lepsch, R. A., Morris, W. , Naftel, J. C., and Cruz, C. I., "Parametric Trade Studies on a Shuttle II Launch System Architecture," NASA TP 3059, 1991.

${ }^{5}$ Miller, C. G., III, and Gnoffo, P. A., "Pressure Distributions and Shock Shapes for $12.84 \%$ On-Axis and Bent-Nose Biconics in Air at Mach 6," NASA TM 83222,1981 .

${ }^{6}$ Miller, C. G., III, "Measured Pressure Distributions, Aerodynamic Coefficients, and Shock Shapes on Blunt Bodies at Incidence in Hypersonic Air and CF $_{4}, "$ NASA TM 84489, 1982.

${ }^{7}$ Vachris, A. F., Jr., and Yeager, L. S., "Quick Geometry-A Rapid Re sponse Method for Mathematically Modeling Configuration Geometry, Applications of Computer Graphics in Engineering," NASA SP-390, 1975, pp. $49-73$.

${ }^{8}$ Miller, C. G., III, Micol, J. R., and Gnoffo, P. A., "Laminar Heat-Transfer Distributions on Biconics at Incidence in Hypersonic-Hypervelocity Flows," NASA TP 2213, 1984

${ }^{9}$ Miller, Charles G., III, "Comparison of Thin-Film Resistance HeatTransfer Gauges with Thin-Skin Transient Calorimeter Gauges in Conventional Hypersonic Wind Tunnel," NASA TM 83197, 1981.

${ }^{110}$ Buck, G. M., "An Imaging System for Quantitative Surface Temperature Mapping Using Two-Color Thermographic Phosphors," presented at ISA 34th International Instrumentation Symposium, 1988

${ }^{1}$ Buck, G. M., "Surface Temperature/Heat Transfer Measurement Using a Quantitative Phosphor Thermography System," AIAA Paper 91-0064. Jan. 1991.

${ }^{12}$ Merski, N. R., "A Relative-Intensity Two-Color Phosphor Thermography System." NASA TM 104123, 1991.

${ }^{13}$ Miller, C. G., "Langley Hypersonic Aerodynamic/Aerothermodynamic Testing Capabilities-Present and Future," AIAA Paper 90-1376, June 1990.

${ }^{14}$ Horvath, T. J., Rhode, M. N., and Buck, G. M., "Aerothermodynamic Measurements on a Proposed Assured Crew Return Vehicle (ACRV) Lifting Body Configuration at Mach 6 and 10 in Air," AIAA Paper 90-1744, June 1990

${ }^{15}$ Buck, G. M., and Vasquez, P., "An Investment Ceramic Slip-Casting Technique for Net-Form, Precision, Detailed Casting of Ceramic Models," NASA Case No. LAR 14471-1, April 1990

I"Cooke, W. J., and Felderman, E. J., "Reduction of Data from ThinFilm Heat Transfer Gages: A Concise Numerical Technique," AlAA Journal, Vol, 4, No. 3, 1966, pp. 561, 562 .
${ }^{17}$ Miller, C. G., [I], "Experimental and Predicted Heating Distributions for Biconics at Incidence in Air at Mach 10" NASA TP 2334, 1984.

${ }^{18}$ Miller, C. G., "Experimental Investigation of Gamma Effects on Hea! Transfer to a 0.006 Scale Shuttle Orbiter at Mach 6," AIAA Paper 82-0826, June 1982

${ }^{19}$ Fay. J. A., and Riddell, F. R., "Theory of Stagnation Point Heat Traunfer in Dissociated Air." Journal of Aeronautical Sriences, Vol 25, No. 2,1958.

${ }^{20}$ Schultz, D. L., and Jones, T. V., "Heat-Transfer Measurements in ShortDuration Hypersonic Fucilities," AGARD AG-165. Feb. 1973.

${ }^{21}$ Cooke, J C. "An Axially Symmetric Analogue for Three-Dimensional Boundary Layers," R. \& M. 3200, British Aeronautical Research Council, 196I.

${ }^{22}$ Hamilton, H. H., II, DeJarnette, F. R., and Weilmuenster, K. J., "Application of Axisymmetric Analogue for Calculating Healing in ThreeDimensional Flows," AIAA Paper 85-245, Jan. 1985

${ }^{23}$ Weilmuenster, K J., and Hamilton, H. H. HI, "Calculations of Inviscid Flow over Shuttle-like Vehicles at High Angles of Attack and Comparisons with Experimenial Iata." NASA TP-2103, May 1983.

${ }^{24}$ Zoby, E. V. Moss, J. N., and Sutton, K., "Approximate Convective Heating Equations for Hypersonic Flow," Journal of Spacec raft and Rockets, Vol. 18, No. I, 1981, pp. 64-70

${ }^{25}$ Hamilton, H. H, 11, Greene, F, and Weilmuenster, K. J., "Comparison of Heating Calculations with Experimental Data on a Modified Shuttle Orbiter,' Journal of Spacecrafi and Rockets, Vol. 29, No. 2, 1992, pp. 208-214

${ }^{26}$ Gnoffo, P. A., "Application of Program LAURA to Three-Dimensional AOTV Flowfields," AIAA Paper 86-0565, Jan. 1986.

${ }^{27}$ Gnoffo, P. A., and McCandless, R. S., "Three-Dimensional AOTV Flowfields in Chemical Nonequilibrium," AlAA Paper 86-0230, Jan. 1986

${ }^{28}$ Gnoffo, P. A., and Greene, F. A., "A Computational Study of the Flowfield Surrounding the Aeroassist Flight Experiment Vehicle," AIAA Paper 87-1575. June 1987

${ }^{29}$ Gnoffo, P. A., "A Code Calibration Program in Support of the Aeroassist Flight Experiment," AlAA 89-1673, June 1989.

${ }^{3 !}$ Throckmorton, D. A., and Hartung, L. C., "Analysis of Entry Aerodynamic Heat Transfer Data for the Orbiter Wing Lower Surface," AIAA Paner 84-0227, Jan. 1984

${ }^{31}$ Hartung, L. C., and Throckmorton, D. A., "Computer Graphic Visualization of Orbiter Lower Surface Boundary-Layer Transition," AIAA Paper 84-0228, Jan. 1984

${ }^{32}$ Dye. W. H. "Heat Transter Phase Change Paint Tests of $0.0175-$ Scale Models (Nos. $21-($ ) and 46-0) of the Rockwell International Space Shuttle Orbiter in the AEDC Tunnel B Hypersonic Wind Tunnel (Test OH 25A)," NASA CR-141,546, July 1975.

${ }^{33}$ Wells, W. L., "Healing Measurements on Space Shuttle Orbiter Models with Differentially Deflected Elevons," NASA TM 84646, May 1983.

K. L. Weilmuenster Associate Editor 